Loma Linda University

TheScholarsRepository@LLU: Digital Archive of Research, Scholarship \& Creative Works

Loma Linda University Electronic Theses, Dissertations \& Projects

$8-1-2012$

\title{
Qualitative Study of Psychosocial Needs for Individuals with Lung Cancer
}

Kevin R. Criswell

Loma Linda University

Follow this and additional works at: http://scholarsrepository.llu.edu/etd

Part of the Clinical Psychology Commons

\section{Recommended Citation}

Criswell, Kevin R., "Qualitative Study of Psychosocial Needs for Individuals with Lung Cancer" (2012). Loma Linda University Electronic Theses, Dissertations \& Projects. 77.

http://scholarsrepository.llu.edu/etd/77

This Thesis is brought to you for free and open access by TheScholarsRepository@LLU: Digital Archive of Research, Scholarship \& Creative Works. It has been accepted for inclusion in Loma Linda University Electronic Theses, Dissertations \& Projects by an authorized administrator of TheScholarsRepository@LLU: Digital Archive of Research, Scholarship \& Creative Works. For more information, please contact scholarsrepository@llu.edu. 


\section{LOMA LINDA UNIVERSITY \\ School of Behavioral Health \\ in conjunction with the \\ Faculty of Graduate Studies}

\section{A Qualitative Study of Psychosocial Needs for Individuals with Lung Cancer \\ by}

Kevin R. Criswell

A thesis submitted in partial satisfaction of the requirements for the degree

Master of Arts in Clinical Psychology

August 2012 
(C) 2011

Kevin R. Criswell

All Rights Reserved 
Each person whose signature appears below certifies that this thesis in his/her opinion is adequate, in scope and quality, as a thesis for the degree Master of Arts.

, Chairperson

Jason E. Owen, Associate Professor of Clinical Psychology

Adam L. Arechiga, Director of Clinical Training, PsyD Program, Assistant Professor of Psychology

Kendal C. Boyd, Assistant Professor of Psychology 


\section{ACKNOWLEDGEMENTS}

I would first like to thank Dr. Jason Owen for his patience and support throughout the process of crafting my thesis proposal and defense. His support was instrumental in the successful defense of my thesis.

I would also like to like to thank my wife, Lisa, for her patience, love, understanding, and support she showed me throughout the long nights of typing, listening to my own frustrations, and doing things as simple but so helpful as housework that I should do, while still having her own obligations in her own doctoral program for Clinical Psychology. You are appreciated and loved, wholeheartedly.

To my family, your interest, positive feedback, and pride in me have propelled me so far. It warms me when I visit with our family and friends and they report hearing all the things that I do to make you proud. It is with the deepest gratitude that I say "Thank you" to you.

I finally want to express my gratitude to Drs. Kenny Boyd and Adam Arechiga for being willing to read through yet another long document that a student wrote, to provide their thoughtful feedback, and to demonstrate flexibility in their schedules to attend my proposal and defense of this thesis. 


\section{CONTENT}

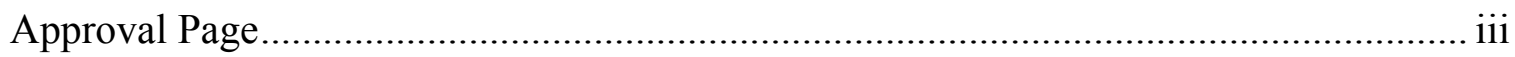

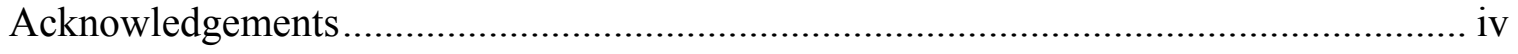

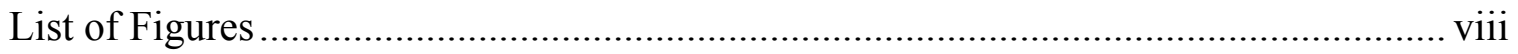

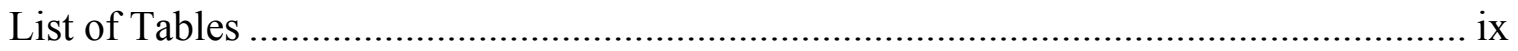

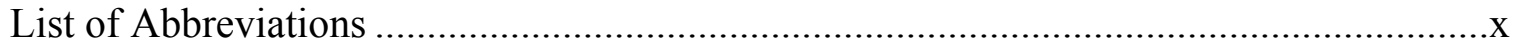

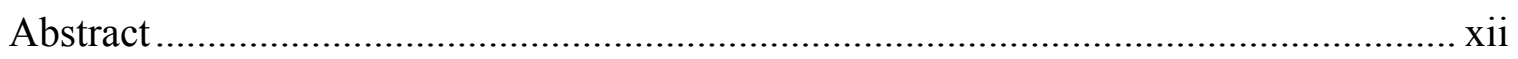

Chapter

1. Background and Significance …………………….......................................

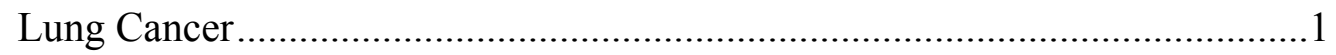

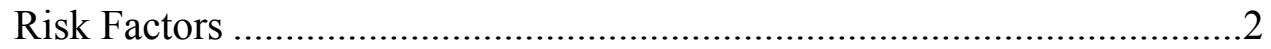

Psychosocial Issues in Lung Cancer ..............................................................

Prevalence of Psychosocial Issues ..............................................................

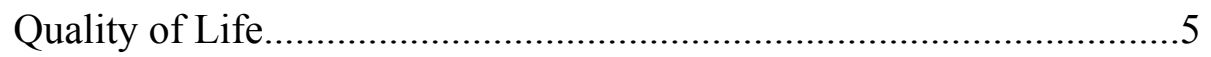

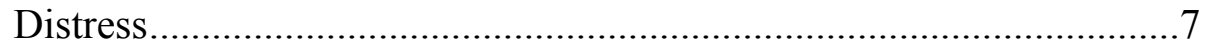

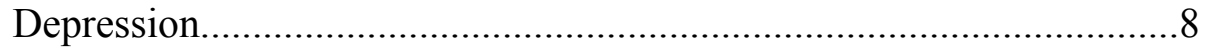

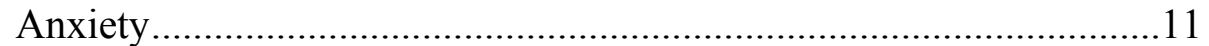

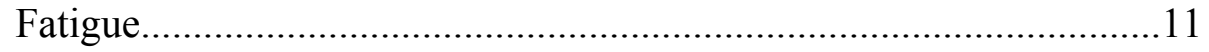

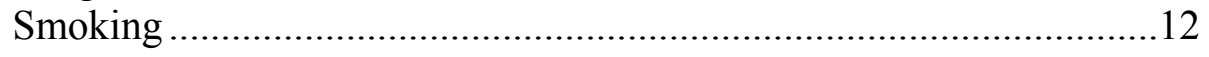

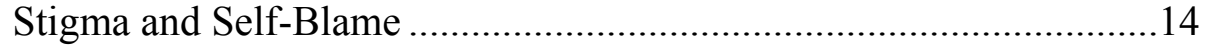

Interventions Offered to Address Psychosocial Needs ................................16

Barriers to Access and Maintain Engagement in Psychosocial

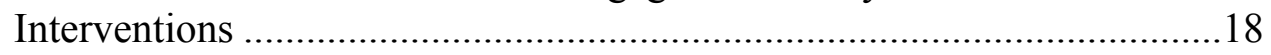

Theories Used to Guide Investigations of Psychosocial Issues ..................19

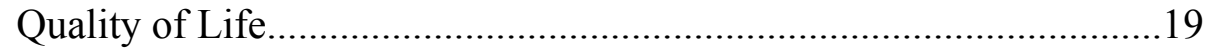

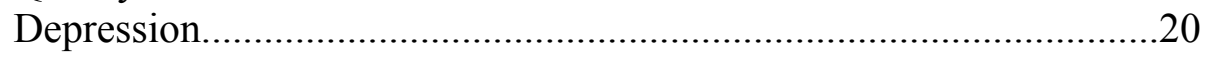

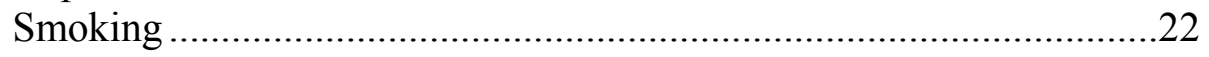

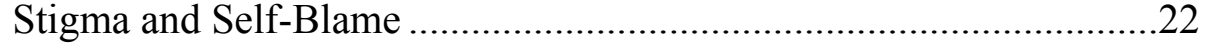


Summary of Psychosocial Needs, Interventions, and Barriers to

Engage in Interventions

Lung Cancer Patients' Experience of Psychosocial Needs.......................26

Lung Cancer Patients' Levels of Interest in Psychosocial Services ..........27

Barriers to Engage in Psychosocial Interventions ..................................27

Developing Effective Interventions: The PRECEDE-PROCEED

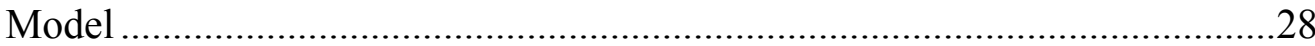

The Importance of the Target Population's Perspective in Current Lung Cancer Intervention Development ....................................31

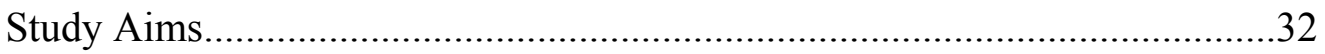

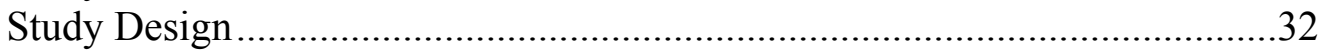

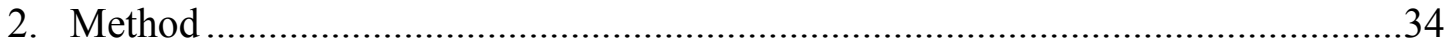

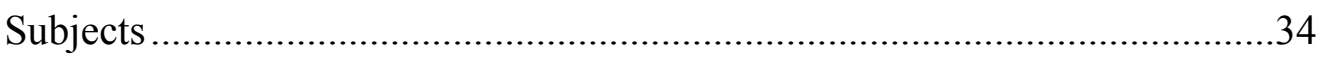

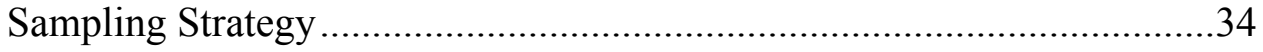

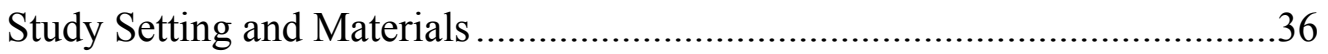

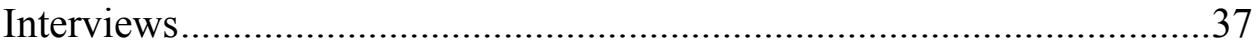

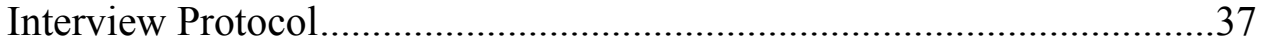

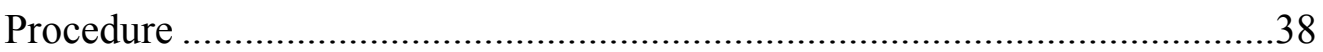

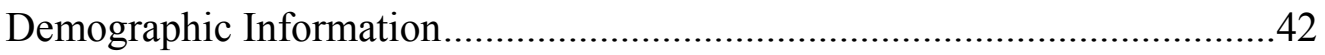

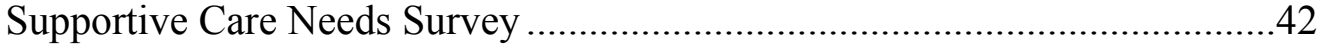

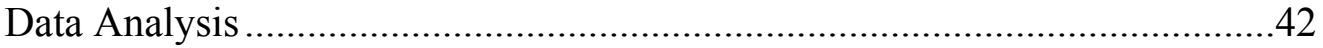

Quantitative Data Analysis ............................................................43

Qualitative Data Analysis ...............................................................44

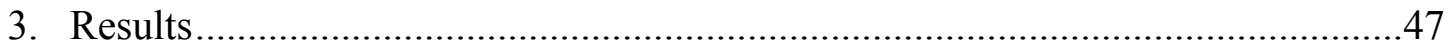

Characteristics of the Study Sample ...................................................4 47

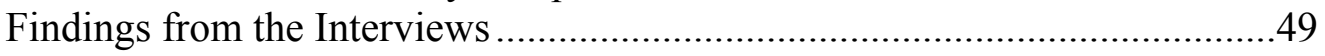

The Most Pertinent Psychosocial Issues of Lung Cancer Patients ............49

Barriers that Hinder Engagement in Psychosocial Interventions ..............51

The Most Desired Methods of Psychosocial Intervention Delivery ..........53

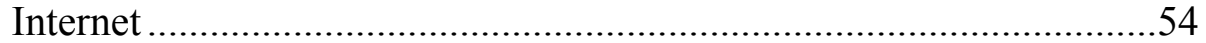

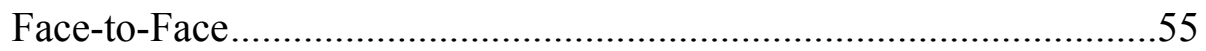




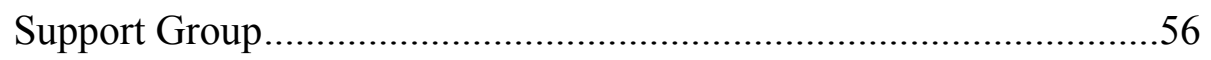

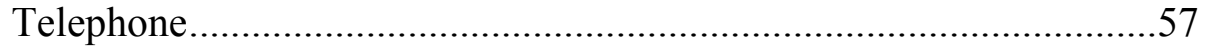

Personal Effort .............................................................................58

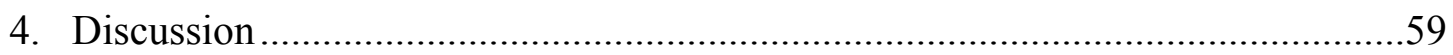

Lung Cancer Patients’ Most Pertinent Psychosocial Needs ...........................59

Barriers that Hinder Lung Cancer Patients' Engagement in

Psychosocial Interventions....................................................................60

Lung Cancer Patients' Interest in Specific Modes of Intervention

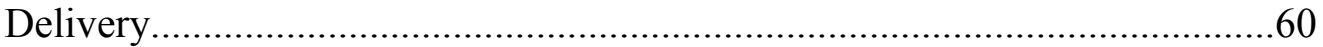

Internet-based Format ..................................................................61

Telephone-based Format...............................................................61

Support Group Format ..................................................................61

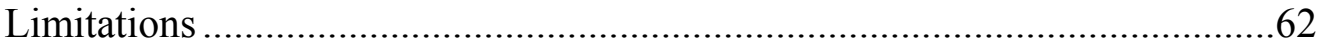

Implications for Psychosocial Intervention Development for Lung Cancer Patients..................................................................................62

Implications for Future Research ...................................................6 63

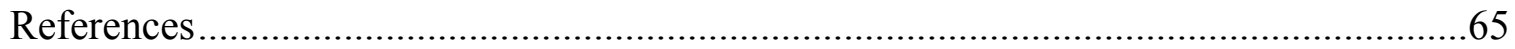

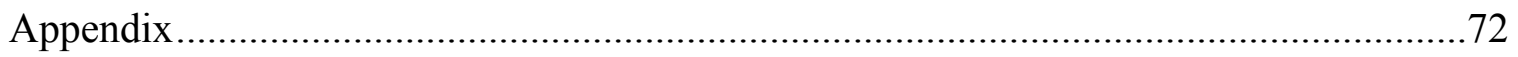




\section{FIGURES}

Figures $\quad$ Page

1. Flowchart of Recruitment and Attrition in the Current Study .............................39

2. Process of Qualitative Data Analysis Used in the Current Study ........................45

3. Frequency of Psychosocial Issues Reported by the Study Sample .......................50

4. Frequency of Barriers reported by the Study Sample .......................................53

5. Average Interest Ratings for Psychosocial Delivery Methods .............................54 


\section{TABLES}

Tables $\quad$ Page

1. Demographic and Medical Characteristics of the Study and Reference

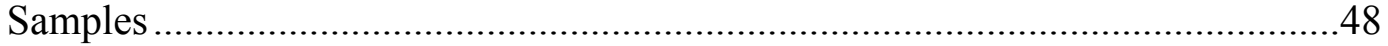

2. Emergent Theme Descriptions and Examples of Barriers to Intervention

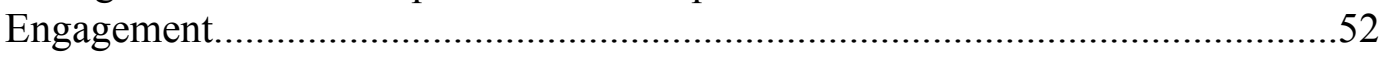


ABBREVIATIONS

ACS

NSCLC

SCLC

QoL

EORTC QLQ-C30

FACT-G

QLQ-LC13

FACT - L

CES-D

HADS

DSM-III-R

SCID

BSI

FSS

CLCSS

SIS

SSGS

PCRS

GT

LLUMC
American Cancer Society

Non-small cell lung cancer

Small cell lung cancer

Quality of life

European Organization for Research and Treatment of Cancer Quality of Life Questionnaire

Functional Assessment of Cancer Therapy - General Version

Quality of Life Questionnaire - Lung Cancer 13

Functional Assessment of Cancer Therapy - Lung Version

Center for Epidemiological Studies Depression Scale

Hospital Anxiety and Depression Scale

Diagnostic and Statistical Manual of Mental Disorders third ed., revised

Structured Clinical Interview

Brief Symptom Inventory

Fatigue Severity Scale

Cataldo Lung Cancer Stigma Scale

Social Impact Scale

State Shame and Guilt Scale

Perceived Cancer-Related Stigma Scale

grounded theory

Loma Linda University Medical Center 
LLUCC

BOL

SPSS

SCNS

TSCN

SEER
Loma Linda University Cancer Center

Behavioral Oncology Laboratory

Statistics Package for the Social Sciences

Supportive Care Needs Survey

Total supportive care needs

Surveillance, Epidemiology, and End Results Program 


\title{
ABSTRACT OF THE THESIS
}

A Qualitative Study of Psychosocial Needs for Individuals with Lung Cancer by

\author{
Kevin R. Criswell
}

\section{Doctor of Philosophy, Graduate Program in Biochemistry \\ Loma Linda University, August 2012 \\ Dr. Jason E. Owen, Chairperson}

Lung cancer affects many people in the United States, accounting for $14.5 \%$ of cancer cases in 2010. Additionally, it is responsible for more cancer-related deaths than any other cancer type. Those living with lung cancer also experience a higher prevalence of psychological distress and mood problems relative to most other cancer types. Despite the high physical and mental health burden borne by those living with lung cancer, psychosocial research on lung cancer generally lags far behind comparable studies in other cancer populations. Evidence from the few interventions developed specifically for lung cancer patients demonstrate an underutilization of those services, which is inferred from generally low response rates from eligible participants. Although a low participation rate may demonstrate the need to investigate the barriers of participating in interventions, little research on that topic is currently available. Also, it is not clear what factors predict refusal to participate in psychosocial interventions for the lung cancer population, despite the available data on demographic and medical differences between eligible those who did and those who did not participate. Overall, there is limited evidence available for preferred interventions, for favored methods of receiving interventions (e.g., Internet, 
face-to-face, telephone), and for perceived barriers to access and maintain engagement in available psychosocial interventions for lung cancer patients.

A qualitative study that utilizes a grounded theory approach to the analysis of interview data from lung cancer patients can address the current gap in understanding of lung cancer patients' perspective on three specific areas: 1) the most important psychosocial needs to address and what factors contribute to higher importance, 2) interest in different psychosocial services and what factors contribute to low and high interest, and 3) what factors serve as barriers to engage in psychosocial interventions. Elucidating these three areas will increase researchers' understanding of lung cancer patients' perspectives via the development of a grounded theory, which investigators can utilize to better address the psychosocial and quality of life needs of this cancer population. 


\section{CHAPTER ONE \\ BACKGROUND AND SIGNIFICANCE}

\section{Lung Cancer}

Lung cancer is projected to be the most diagnosed cancer at 222,520 new cases in the USA in 2010 (American Cancer Society [ACS], 2010). Responsible for an estimated 157,300 deaths in the U.S. in 2010, lung cancer has the highest mortality of any cancer type (ACS, 2010). Out of 789,620 new cancer diagnoses for males and 739,940 for females, cancer of the lung is estimated to be the second-most diagnosed cancer in men $(15 \%)$ and women (14\%) in 2010 behind prostate (28\%) and breast cancers $(28 \%)$, respectively (ACS, 2010).

Lung cancer can be separated into two major categories: non-small cell lung cancer (NSCLC) and small cell lung cancer (SCLC). NSCLC and SCLC are different in their prevalence and mortality rate. NSCLC is more commonly diagnosed (85\%) than small cell lung cancer (14\%) (ACS, 2010; combined percentage 99\% due to rounding). The five-year survival rate for patients with NSCLC (17\%) is higher than patients diagnosed with SCLC (6\%).

Unfortunately, the five-year survival rate for lung cancer has remained at the same low level from 1975 to 1986 (13\%) with a slight increase between 1999 and 2005 $(16 \%)$. This increase in survival is likely related to a combination of factors, which include a decrease in overall smoking rates in the past 40 years and improved techniques (e.g., spiral computed tomography scanning) for detecting lung cancer in early stages within high-risk populations. However, it has been noted that evidence for the contribution of advances in early detection techniques is still being collected and has not 
yet been proven to reduce mortality in lung cancer (ACS, 2010). When compared to the national average across cancer types in 1999-2005 (68\%), the five-year survival rate for lung cancer is much lower. This difference can be attributed to a combination of factors related to lung cancer diagnoses that are typically made at a late stage of the disease, which can be due to such factors as ambiguous symptoms (e.g., an unusual cough) and aspects related to lung cancer screening (e.g., not wanting a bronchoscopy; ACS, 2010; Yardley, Davis, \& Sheldon, 2001). Generally, a later stage of cancer implies that the cancer has spread beyond the initial cancer site to the surrounding tissues or lymph glands (regional stage) or metastasized to separate organs (distant stage). As the cancer progresses to later stages, it becomes increasingly difficult to effectively neutralize the cancer cells. Because only $15 \%$ of lung cancer cases are initially diagnosed at a local stage (ACS, 2010), it is logical that the survival rate is low.

\section{Risk Factors}

Cigarette smoking has been determined to be the most salient risk factor for contracting lung cancer. It has been demonstrated that the relative risk of developing lung cancer increases with the duration and amount of the smoking. Although other airborne substances (e.g., secondhand smoke, asbestos, talcum powder, and pollution) have been found to contribute to the development of lung cancer, smoking cigarettes has received the most attention from healthcare professionals and the public (American Cancer Society [ACS], 2010). In their lifetimes, about $17.2 \%$ of male and $11.6 \%$ of female smokers (14.4\%, combined) will develop lung cancer, and smoking behavior has 
been found to be attributable to about $90 \%$ of lung cancer cases (Alberg \& Samet, 2003; Villeneuve \& Mao, 1994).

\section{Psychosocial Issues in Lung Cancer}

Several reviews have identified areas of psychosocial need in lung cancer, which include quality of life, depression, distress, and smoking cessation. In addition to those psychosocial issues, the constructs of stigma, self-blame, and guilt are gaining increasing attention in the literature (Bedor, Alexander, \& Edelman, 2005; Carlsen, Jensen, Jacobsen, Krasnik, \& Johansen, 2005; Joyce, Schwartz, \& Huhmann, 2008). Although stigma has been documented across cancer types, it seems lung cancer patients experience more perceived cancer-related stigma relative to breast and prostate cancer patients (Loconte, Else-quest, Eickhoff, Hyde, \& Schiller, 2008); stigma in lung cancer may also serve as a barrier to seeking care when symptoms of the disease are first detected by the patient (Chapple, Ziebland, \& McPherson, 2004). Self-blame and guilt were documented in the experiences of lung cancer patients, yet levels of these constructs seem to be explained more by a history of smoking than being diagnosed with a specific cancer type (LoConte et al., 2008). However, levels of self-blame and guilt is likely to be high in lung cancer patients because about $90 \%$ of all lung cancer cases can be attributed to a history of smoking (American Cancer Society [ACS], 2010).

When compared to other cancer types, lung cancer patients have experienced relatively greater levels of unmet need (Li \& Girgis, 2006) and higher levels of psychological distress when compared to other cancer types (Zabora, Brintzenhofeszoc, Curbow, Hooker, \& Piantadosi, 2001). In an investigation using United States 
population-based data, individuals diagnosed with lung cancer, female reproductive cancer, other, and multiple cancer diagnoses demonstrated the highest levels of distress, as measured by the Kessler-6 (Kaiser, Hartoonian, Owen, 2010). In an investigation of significant independent correlates of high levels of supportive care needs in a sample of lung cancer patients, higher levels of need were associated with greater trauma, greater symptom burden, lower satisfaction with health care, and lower levels of physical functioning (Sanders, Bantum, Owen, Thornton, \& Stanton, 2010). As a subpopulation of cancer patients who demonstrate relatively high levels of poor psychosocial outcomes related and high levels of unmet needs, it has been important to meet those needs with interventions that are tailored for lung cancer patients (Carlsen et al., 2005).

This review of the current state of the literature on psychosocial needs and interventions for lung cancer patients will focus primarily on quality of life, distress, depression, anxiety, smoking, and the cluster of stigma, self-blame, and shame. Since fatigue has also been identified as an important symptom with psychosocial implications, its prevalence will be provided as well. First, the prevalence of each psychosocial issue will be presented, followed by theories utilized to guide studies in this area of the literature, the needs related to the psychosocial issues discussed, interventions implemented to address those needs in samples of lung cancer patients, and barriers to engage in available psychosocial interventions.

\section{Prevalence of Psychosocial Issues}

Generally, lung cancer patients and survivors have demonstrated high rates of clinically relevant psychosocial issues. Unfortunately, the assessment of prevalence rates 
in study samples is often hindered by the absence of clinical cutoffs for scales used.

Characterizing psychosocial issues in lung cancer is further complicated by the utilization of different measurements of constructs and behaviors across studies.

\section{Quality of Life}

Quality of life (QoL) has been defined as a multidimensional construct, encompassing the physiological, psychological, and social wellbeing of a given individual (Fox \& Lyon, 2006; Yang, 2009). Examples of multidimensional scales used to measure quality of life in lung cancer studies include the European Organization for Research and Treatment of Cancer Quality of Life Questionnaire (EORTC QLQ-C30; Bezjak et al., 2008) and the Functional Assessment of Cancer Therapy - General Version (FACT-G; LoRusso et al., 2003). Both of these measures have lung cancer-specific modules, called the QLQ - Lung Cancer 13 (QLQ-LC13 and the FACT - Lung Version (FACT-L), that encompass the impact on QoL from symptoms and treatments that are typical for lung cancer patients (LoRusso et al., 2003). These additional modules add a symptom and treatment burden component to the measurement of QoL that can provide a useful perspective in explaining how $\mathrm{QoL}$ is related to relevant study variables when sampling lung cancer patients. It should be noted that these scales differ slightly in their assumption of the facets that compose QoL. Specifically, the QLQ-C30 is designed to encompass five functional domain facets (i.e., Physical, Role, Social, Emotional, and Cognitive). The FACT-G has four factors of wellbeing (i.e., Emotional, Cognitive, Social, and Physical), which may be similar to the factors of the QLQ-C30. However, it is unclear how these different scales differ with respect to convergent and divergent 
validity with other psychosocial outcome measurements, and future studies are needed to determine whether these scales differ in their results across different subgroups of lung cancer patients (e.g., separated by lung cancer type and stage of cancer) and settings.

Although QoL was defined as a multidimensional construct and measured using scales that encompass multiple facets of QoL, some studies used single-item measures of QoL (Gooneratne et al., 2007), possibly undermining the generalizability of their findings to other studies that implemented valid measures of the multidimensional construct of QoL. It is certainly preferable to use a measure that reflects the multifaceted conceptualization of QoL along with items that are specific to the treatment because those measurements have been shown to be valid and reliable (Casañas i Comabella, Gibbons, \& Fitzpatrick, 2010).

Comparisons of QoL measures between studies are complex, given the different measurements of the construct used by different investigators. For example, some studies have utilized measures that have been considered to be more general scales of overall well-being (e.g., QLQ-C30), whereas others have used scales more specific to lung cancer symptomology (e.g., LCSS). Therefore, it is difficult to compare findings directly between studies of QoL in lung cancer patients.

Also, the lack of generally accepted criteria for identifying low, moderate, and high levels of QoL in validated measures makes it difficult to determine rates of lung cancer patients who are considered to have a high or low level of QoL. However, efforts (Slotman et al., 2009) were made to quantify levels of lowered QoL over time in SCLC patients $(N=188)$ who decreased at least 20 points (i.e., clinically relevant decrease) from baseline to three months (according to the QLQ-C30) across factors included in the 
scale. Rates of clinically relevant decreases in QoL subscales were as follows: $28.7 \%$ for global health status, $30.3 \%$ for role functioning, $16.5 \%$ for cognitive functioning, and $17.0 \%$ for emotional functioning. Future investigations should incorporate similar methods of quantifying clinically significant levels of QoL to aid reviews of the literature on overall wellbeing in lung cancer patients.

Generally, longitudinal studies of QoL in lung cancer patients show decreases in the various domains of the underlying construct. Although a small subsample of SCLC patients $(n=37)$ who received intravenous chemotherapy experienced a decline in role functioning over time (Naughton et al., 2002), this finding involved a small sample and is limited to a specific treatment and lung cancer type. Future longitudinal investigations of QoL in lung cancer should involve large, nationally-representative samples to bolster the generalizability of results. Although it is not clear as to exactly how great the level of need for QoL interventions is due to the lack of generally-accepted cutoff criteria for sequential levels of the multiple facets of overall wellbeing, the available literature does suggest that lung cancer patients who demonstrate a low performance status, dyspnea, and weight loss (Langendijk et al., 2000) will likely have a higher level of needs related to QoL issues.

\section{Distress}

Distress is understood to be a multidimensional construct that incorporates essentially any distressing area of a cancer patient's life (Graves et al., 2007). Distressing areas of the life may include physical health, effects of disease and treatment, and difficulty in social and emotional domains. Interestingly, with such an encompassing 
definition, measurements of distress have included combinations of depression and anxiety levels (Hospital Anxiety and Depression Scale), multiple domains of overall distress (Brief Symptom Inventory), and simple one-item Likert scale measures (Distress Thermometer) to assess the dynamic construct (Graves et al., 2007).

Increases over time in rates of clinical distress have been found in samples of lung cancer patients. In a sample of lung cancer patients, $29 \%(n=52)$ at baseline, $33 \%(n=$ $40)$ at three months, and 35\% $(n=33)$ at six months were found to meet cutoff criteria for clinically significant levels of distress (Badr, Acitelli, \& Taylor, 2008). In a large sample of mixed cancer diagnoses $(N=4496)$, lung cancer patients $(n=629)$ achieved the highest rate of clinical distress (as measured by the Brief Symptom Inventory) compared to all other cancer types in the sample (43.4\%; Zabora et al., 2001). A larger rate of clinical distress (61.6\%) was found in distress screening study of lung cancer patients ( $n$ = 333; Graves et al., 2007). However, this study noted that 134 of the study sample had not received a definitive diagnosis of lung cancer, potentially undermining the results. Evidence has been found for increased severity of distress over time (Aubin et al., 2010), but small sample sizes limit the validity of this finding.

\section{Depression}

Some studies consider depression to be a multidimensional construct that is manifested through bidirectional interactions between biological, psychological, and social variables (i.e., the biopsychosocial model is inferred to conceptualize the role of depression; Lo et al., 2010). Other studies have adhered closely to the conceptualization of depression set forth by the Diagnostic and Statistical Manual of Mental Disorders 
(Spitzer, Williams, Gibbon, \& First, 1990) third ed., revised criteria that was current at the time of the study (Nakaya et al., 2006; Uchitomi et al., 2003). However, large discrepancies between rates of clinically significant depression have developed between using the Structured Clinical Interview and other validated measurements, such as the Center for Epidemiological Studies Depression Scale (CES-D), the Beck Depression Inventory (BDI) and the Hospital Anxiety and Depression Scale (HADS).

Using the CES-D cutoff, 33-38.9\% of lung cancer samples met the cutoff for a clinically significant level of depressive symptoms (Gonzalez \& Jacobsen, 2010; Hopwood \& Stephens, 2000; Kurtz, Kurtz, Stommel, Given, \& Given, 2002). A slightly lower rate of depression $(28.6 \%$ of $n=119)$ was found in a sample of early-stage female NSCLC patients (Sarna et al., 2010). Interestingly, a similar prevalence of severity of depressive symptoms (30\%) has been found in a sample of spouses of lung cancer patients (Kim, Duberstein, Sorensen, \& Larson, 2005). Other studies have reported much lower prevalence rates for the presence of clinically significant depression in lung cancer patients (between 4.7-8\%), which is likely due to using the Structured Clinical Interview for the DSM-III-R (SCID) to assess for depression and to being a Japanese sample (Nakaya et al., 2006; Uchitomi et al., 2003). Also, low rates of depression in lung cancer samples have been found when using the strict criteria of "definite depression" when using the HADS scale (3\%; Myrdal, Valtysdottir, Lambe, \& Ståhle, 2003). LoConte et al. (2008) found a significant inverse quadratic trend in depressive symptom severity over time in a subsample of lung cancer patients $(n=52)$, with the highest levels seen at two months since the start of the study when using the depression subscale of the HADS. It should be noted that the LoConte et al. study limited the sample to stage IV NSCLC 
patients. It is possible that that finding was spurious due to the absence of significant quadratic trends being found in other longitudinal studies of depression in lung cancer (Hopwood \& Stephens, 2000). However, trends of increasing severity of depressive symptoms over time have been found (Henoch, Bergman, Gustafson-Johansson, \& Danielson, 2007), suggesting a linear increase in depression in lung cancer patients over time. However, When nearing the end of life at advanced stages of lung cancer, it has been demonstrated that a significant quadratic relationship exists between levels of depression and time to death, where depressive symptoms are at their lowest level of severity at 20 months until death and steadily increase in a curvilinear fashion toward time of death (Lo et al., 2010). However, this finding has not been replicated in other longitudinal studies that have included depression measures.

There is evidence that levels of depression are positively related to mortality in lung cancer (Buccheri, 1998; Chen, Chen, \& Yu, 2010). However, this finding has been debated in the literature with null findings from other studies (Nakaya et al., 2006). It is possible that lung cancer patients who adopt a depressive coping strategy and have lower performance status have a shorter life-expectancy (Faller \& Schmidt, 2004), indicating that it may not simply be the presence of depressive symptoms that predicts shorter survival (depression levels as measured by the HADS depression subscale was not a significant predictor of survival time in the same study). It is also possible that the contradiction in findings reflects the unknown longitudinal relationship between depression, symptom burden, and survival. Clearly, rigorous longitudinal studies that investigate survivorship in lung cancer patients need to be conducted. 


\section{Anxiety}

Studies that have included anxiety in investigations of psychosocial aspects of lung cancer have not explicitly defined anxiety. It can be inferred from the frequent use of specific scales (e.g., the Hospital Anxiety and Depression Scale) that anxiety is considered to be a facet of overall distress. This anxiety refers to subjective feelings of worry that give rise to pathological levels of clinical distress.

Myrdal et al. (2003) found that $43 \%$ of the sample of lung cancer patients $(n=$ 112) met the cutoff for possible clinical anxiety (as measured by the HADS). Using the same measurement, a lower percentage of the lung cancer sample met the criteria for definite clinical anxiety in another study (16\% of 82 lung cancer patients; Montazeri, Gillis, \& McEwen, 1998). In the same investigation, lung cancer patients did not vary significantly over time with respect to levels of anxiety from baseline to three months later, suggesting a low level of anxiety over time. However, findings from another investigation of anxiety in lung cancer patients $(N=170)$ suggested that $43.3 \%$ of their study sample reported clinically significant levels of anxiety (as measured by an authorconstructed scale; Buchanan, Milroy, Baker, Thompson, \& Levack, 2010). Another study found that $25 \%$ of the lung cancer sample $(n=250)$ met the cutoff for clinically high levels of anxiety (as measured by the Brief Symptom Inventory, BSI; Tchekmedyian, Kallich, McDermott, Fayers, \& Erder, 2003).

\section{Fatigue}

Often considered one of the most commonly reported symptoms by lung cancer patients and survivors, fatigue has been conceptualized as a distressing and subjective 
feeling of a lack of energy, tiredness, and loss of physical strength. Rates of fatigue in lung cancer are generally at or slightly above half of study samples, ranging from 50-59\% (Hung et al., 2011; Okuyama et al., 2001; Stone, Richards, A’Hern, \& Hardy, 2000). However, one study by Hickok, Morrow, McDonald, and Bellg (1996) reported that over three-quarters (78\%) of the study sample of lung cancer patients who received radiotherapy demonstrated clinically relevant levels of fatigue, but this finding is questionable due to the retrospective nature of the methodology, using patients' past medical record to assess for fatigue. One study defined "severe fatigue" as the $95^{\text {th }}$ percentile of scores obtained on the Fatigue Severity Scale (FSS) by an age and gendermatched sample of control subjects without cancer (Stone et al., 2000). However, another study defined "clinical fatigue" as fatigue that interfered with at least one aspect of daily functioning, which may be considered more inclusive when compared to Stone et al. (2000). Certainly, efforts need to be made to standardize measurements and generally recognized clinical cutoffs for fatigue.

\section{Smoking}

Studies have typically differentiated between current (i.e., currently smoking at the time of the study), former (i.e., did not smoke at the time of the study but did smoke before), and never smokers (i.e., never smoked before or during the time of the study). Former smokers tend to make up the majority of the study samples (37-80.2\%), whereas current (11.5-50\%) and never (8.3-13\%) smokers composed smaller fractions of study samples (Balduyck et al., 2011; Gonzalez \& Jacobsen, 2010; LoConte et al., 2008). 
Estimates of relapses in smoking post-treatment have varied widely (30-60\%; Pinto, Eakin, \& Maruyama, 2000; Walker, Larsen, Zona, Govindan, \& Fisher, 2004). Measurements of smoking behavior vary across studies. Some investigators seemed to choose their measures based on a model under scrutiny, such as a model consisting of smoking urges and social support (Walker et al., 2004). Studies have also used author-created questionnaires to determine current smoking status, age of first tobacco use, and number of pack years (i.e., the number of packs smoked in one day multiplied by the number of years as a smoker) of study samples. Some studies have also used biological indicators of smoking status at the time of the study (e.g., urinary cotinine; Cooley et al., 2007), using the biological markers as indicators of smoking status when discrepancies exist between self-report questionnaires and the biological indicators. Clearly, a consensus on how to measure smoking behavior in lung cancer has not been reached. These differences in measurement may be partly to blame for the variability in reported smoking rates in the literature.

Primary prevention of smoking behavior can substantially decrease the prevalence and mortality due to lung cancer because $90 \%$ of the cases of lung cancer can be traced to the use of tobacco (Alberg \& Samet, 2003). Despite a history of smoking, studies have shown that cessation of smoking behavior can reduce the probability of contracting lung cancer, having a recurrence of cancer, or dying from the disease (Anthonisen et al., 2005; Wu \& Sin, 2011). With the steeper decline seen in tobacco use in men compared to women from 1997 - 2006 (Jemal et al., 2008), lung cancer mortality has been declining at a greater rate for men than for women. If such a trend were to continue, women may surpass men in the number of cancer deaths. In summary, lung cancer patients 
demonstrate a need for interventions aimed at ceasing the use of tobacco, especially in female lung cancer patients with a history of smoking.

\section{Stigma and Self-Blame}

Some lung cancer patients attribute the cause of their cancer to their behavior (Faller, Schilling, \& Lang, 1995) and experience feelings of being labeled as "dirty" or "undesirable" (Chapple et al., 2004) because of their identity as lung cancer patients. Stigma has been conceptualized as a normative label (Menec \& Perry, 1995) that implies an undesirable or flawed quality. This label can be externally imposed by others; in the case of the lung cancer patient, others might assume that the individual smoked, which contributed to the development of the cancer. In this way, lung cancer patients may perceive that others blame them for their disease. In one investigation, stigma was conceptualized in lung cancer as "health-related stigma," which is a subjective experience of rejection or devaluation based on an identifiable label stemming from a healthcondition (e.g., the label of "lung cancer patient or survivor" and being rejected due to that connection with the chronic health condition; Cataldo, et al., 2011). Interestingly, inherent in most investigations of stigma is the concept of self-blame for contracting the disease, whether the feeling was imposed by the stigma from others or stemmed from personal thoughts or feelings (Faller et al., 1995; Chapple et al., 2004; Cataldo et al., 2011).

Self-blame (also, personal blame) has been considered as attributing personal responsibility for a given condition (e.g., contracting lung cancer; Faller et al., 1995). Not as often studied as stigma, self-blame has been clustered together with stigma 
(Chapple et al., 2004), More research is needed to establish whether self-blame should be studied separately from stigma or if self-blame should be always included in investigations of stigma in lung cancer.

Measurements of stigma and self-blame in lung cancer patients vary across studies, making it difficult to compare results. Complications in interpreting results of studies arise from the low availability of measurements that have demonstrated validity in lung cancer patient samples. The Cataldo Lung Cancer Stigma Scale (CLCSS) is the only measure of cancer-related stigma that was normed on a sample of lung cancer patients (Cataldo et al., 2011). Four subscales are in this measure: 1) stigma and shame, 2) social isolation, 3) discrimination, and 4) smoking. Other measures of stigma, selfblame, and guilt include the Social Impact Scale (SIS; Gonzalez \& Jacobsen, 2010), the State Shame and Guilt Scale (SSGS), and the Perceived Cancer-Related Stigma Scale (PCRS; LoConte et al., 2008).

Quantifying the rate of lung cancer patients who experience a clinically significant level of stigma or self-blame has begun recently with the availability of measures to assess such constructs (e.g., Cataldo et al., 2011). Implying self-blame, 70\% of lung cancer patients (while 63\% indicated on a questionnaire in the same study) who were interviewed attributed their smoking behavior as a cause of their lung cancer (Faller et al., 1995). However, this statistic must be compared to quantitative stigma data gathered in future studies of lung cancer samples. Although, no studies have utilized cutoff scores to separate more severe from less severe cases of stigma, self-blame, and shame, one study demonstrated that patients with NSCLC experienced a significantly higher level of perceived cancer-related stigma relative to breast and prostate cancer 
patients, but blame and guilt averages did not differ across cancer groups (LoConte et al., 2008). Interestingly, blame and guilt scores were predicted by having a history of smoking and not by type of cancer.

\section{Interventions Offered to Address Psychosocial Needs}

Available literature documenting the effectiveness of psychosocial interventions for lung cancer patients is lacking in comparison to the high level of psychosocial need in this cancer population. Interventions have focused mainly on reductions in distress, cessation of smoking, and increase in QoL. No literature was found on psychosocial interventions that target anxiety; depression; and stigma, self-blame, and shame in lung cancer patients.

The effectiveness of interventions targeting psychosocial issues in lung cancer is mixed: Interventions aimed at smoking cessation show little or no intervention effects; yet QoL, dyspnea (Bredin et al., 1999), and distress interventions generally show improvements in the outcomes measured. For example, a combination supportive care and chemotherapy intervention resulted in longitudinal improvements in social and global QoL (Helsing, Bergman, Thaning, \& Hero, 1998). Also, a QoL screening intervention and early palliative care resulted in more discussion about QoL issues that concerned lung cancer patients (Jacobsen et al., 2011; Taenzer et al., 2000; Temel et al., 2010). Finally, rates of clinically significant distress (as measured by the DT) were shown to be significantly lower in a group who received an extensive distress screening in addition to a referral to talk with a member of a psychosocial team (30.7\%), when compared to two other groups who received either the more extensive distress screening (50.9\%) or the 
minimal screening (51.3\%; Carlson, Groff, Maciejewski, \& Bultz, 2010). Given the prevalence rates for depression; anxiety; fatigue; and stigma, self-blame, and guilt, it is necessary to develop interventions that effectively target those psychosocial issues. Additionally, areas of improvement should be identified for interventions delivered (e.g., targeting smoking behavior) to increase the treatment effects.

Response rates have also varied across intervention trials. Some have reported perfect response rates, and other studies have not reported any response rate for lung cancer patients who participated (Bredin et al., 1999; Helsing et al., 1998; Temel et al., 2010). However, the response rates for most interventions that target improvement of psychosocial outcomes in lung cancer are in the range of 33.5-53.3\% (Jacobsen et al., 2011; Porter et al., 2011; Taenzer et al., 2000). Clearly, the literature on psychosocial interventions for lung cancer patients suffers from a lack of reporting the response rates of trials. Since most interventions that include the response rate indicate that about half or fewer eligible lung cancer patients participate, the development of future interventions may benefit from a qualitative investigation regarding the reasons why lung cancer patients decide to not take part in supportive care services offered to them. Gaining insight into the perspective of the lung cancer patient can help direct future development of research studies to be tailored more effectively to the needs and preferences of the target population.

In summary, lung cancer patients have a high level of need in multiple psychosocial domains, yet it is unknown why eligible patients tend to not participate in intervention trials. It is evident that most lung cancer patients are interested in at least one form of supportive care service (91.4\%) and about $20 \%$ were interested in attending a 
lung cancer support group (Sanders, Bantum, Owen, Thornton, \& Stanton, 2010).

However, Owen, Goldstein, Lee, Breen, \& Rowland (2007) found that only .03\% $(n=5)$

of lung cancer patients utilized a cancer-related support group. Because most (92.2\%) of those patients perceived benefit from attending a cancer-related support group, understanding the barriers to access and maintain engagement in interventions can lead to higher rates of utilization of supportive care services that patients typically perceive to be beneficial.

\section{Barriers to Access and Maintain Engagement in Psychosocial Interventions}

Very little research has been dedicated to exploring the reasons why lung cancer patients might experience difficulty in accessing and maintaining engagement in psychosocial interventions developed for their needs. With the exception of one investigation of the difference between lung cancer patients' and support group facilitators' perceptions of barriers to access a support group (Devitt et al., 2010), no research has been conducted on this topic for lung cancer. Although it is likely that factors such as high symptom burden, mortality, and not meeting eligibility criteria can contribute to hindering lung cancer patients' involvement in psychosocial interventions, such hypotheses have yet to be systematically tested.

Results from qualitative research suggest several potential barriers to accessing and maintaining engagement in interventions. For example, a lung cancer patient reported that she feared that she would be refused cancer treatment because she was a smoker (Chapple et al., 2004). Also, there is some evidence that stigma and self-blame 
may be related to social isolation (Greene \& Banerjee, 2006), indicating that lung cancer patients with high levels of personal blame may tend to not seek help for unmet needs. Finally, Devitt et al. (2010) found that lung cancer patients perceived the group environment, discussing their cancer, parking, and travel as potential barriers to access a support group. However, further evidence must be gathered to better understand what drives lung cancer patients' decisions about participating in available interventions. Ideally, an in-depth analysis of lung cancer patients' difficulties to access and maintain engagement in interventions would inform the development of interventions, improving the response rates of services offered.

\section{Theories Used to Guide Investigations of Psychosocial Issues}

Overall, the literature on psychosocial issues in lung cancer is lacking guidance from theoretical frameworks in the areas of anxiety, distress, and quality of life. Although theories have been found to guide investigations in other psychosocial constructs, they often vary widely in their usage and focus on different outcome variables, complicating comparisons of results across studies. Investigations of distress and anxiety did not report the use of any theoretical models to guide aims and hypotheses.

\section{Quality of Life}

Several studies did not identify a theory or model that guided investigations and interventions involving QoL in lung cancer patients (Helsing et al., 1998; Langendijk et al., 2000; Taenzer et al., 2000; Naughton et al., 2002). Generally, theoretical orientations 
are lacking in investigations of QoL, providing little direction for study hypotheses and aims, which are often chosen based on previous research that suffers from multiple shortcomings already discussed. One investigation highlighted the lack of theoretical orientations used in the psychosocial literature in lung cancer, stating, "With limited theoretical perspectives available, researchers also must turn to the empirical literature for guidance in study efforts in this important and emerging field" (Fox \& Lyon, 2006; p.

932). Within this same investigation, the authors incorporated a relatively young "theory" that they named "the theory of unpleasant symptoms," which considers the importance of identifying "symptom clusters" as units of analysis when testing their effects on other outcome measurements. The use of the model yielded results from a hierarchical "symptom cluster" of depression and fatigue explaining QoL scores $(n=52)$, which concluded with depression explaining a significant amount of the variance and fatigue dropping from significance. Although this result did not provide novel findings, further investigations utilizing this approach along with larger samples and many different, widely used, and valid measurements may help guide future investigations. Theories that incorporate QoL as a factor within their frameworks should be applied more often in the literature to guide hypotheses and conclusions drawn from results.

\section{Depression}

No theories or models were applied in several studies (Hopwood \& Stephens, 2000; Kurtz et al., 2002). However, one study inferred the use of the biopsychosocial model to understand the complexity by which depressive symptoms are manifested and maintained in lung cancer patients (Lo et al., 2010), emphasizing the multitude of factors 
that should be considered in predicting depression. Also, other investigations have used attachment and hope theories.

Attachment theory has been utilized to demonstrate that individuals with chronic illnesses who have not developed healthy expectations of and capacity for social relationships will likely demonstrate higher levels of depression. Within this framework, investigators (Lo et al., 2010) saw the importance of keeping the integrity of the self in the context of advanced cancer, which may help foster higher self-esteem and buffer against depressive symptoms. However, a major limitation in the current use of this theory in lung cancer is the lack of longitudinal data from childhood to corroborate patient self-report of one's attachment to a primary caregiver. Although it may be assumed that relationships between the patient and significant others might characterize the patient's quality of attachment early in childhood (a presupposition of this theory), this assumption should be confirmed for this population.

Also, Hope Theory (Snyder, 2002) was applied to a study of depression in lung cancer patients, predicting higher levels of depressive symptoms with lower levels of hope (as measured by the Adult Hope Scale; Berendes et al., 2010). Hope Theory is a goal-attainment theory, conceptualizing individuals with high levels of "hope" as those who can perceive a greater number of methods to obtain a desired goal (i.e., pathways thinking) and consider themselves as highly capable of pursuing a goal via the perceived pathways to the goal (i.e., agency thinking). It was found that depressive symptom severity was inversely related to levels of hope, implying higher levels of hope predicted lower levels of depressive symptomology. The authors (i.e., Berendes et al., 2010) called 
for further longitudinal research to investigate whether levels of hope continue to predict levels of depression across multiple timepoints.

\section{Smoking}

A model incorporating Appetitive (i.e., desiring positive effects as a result of a behavior) and Aversive (i.e., engaging in a behavior to avoid negative feelings or consequences) urges as well as Directive and Nondirective social support was constructed by Walker et al. (2004) to explain smoking relapse in lung cancer patients who completed treatment for cancer. The theory posits that individuals who did smoke will likely relapse into smoking again if an individual has a high reactance (i.e., a tendency to reject or oppose advice given from others) and experiences directive social support (i.e., advice characterized by being told what to do and giving little choice to the recipient of the support) will likely experience high levels of appetitive urges, leading to higher relapse rates as well as higher levels of depression. Although Walker et al.'s (2004) findings supported the theory, a low sample size $(n=35)$ and lack of replication in the literature raises questions regarding the strength of the theory and its validity in predicting smoking behavior.

\section{Stigma and Self-Blame}

Several studies have guided study hypotheses via attribution theory to explain lung cancer patients' reactions to stigma and self-blame in mixed methods (Faller et al., 1995) and cross-sectional quantitative research. Menec's and Perry's (1995) study was helpful in providing information regarding the feelings of anger, pity, responsibility, and 
willingness of individuals without chronic illnesses (i.e., $N=249$ introductory psychology students at a Canadian school) to provide aid to younger or older individuals of 10 selected "stigmas" (i.e., conditions that are considered undesirable or generally looked down upon by society). As lung cancer was included as one of these stigmas, the study provided an opportunity for researchers to understand how an educated population of young adults (mostly female) viewed young and old individuals with lung cancer, based on level of controllability (i.e., whether the individual with the stigma was able to influence its etiology). The results suggested that older lung cancer patients were viewed with significantly more pity and evoked less anger than younger lung cancer patients. However, the effect of controllability predicted more pity, less anger, less attribution of responsibility, and more willingness to help for lung cancer patients who had scenarios that depicted an uncontrollable condition. The results of this study were corroborated by a qualitative study (Chapple et al., 2004), which demonstrated that older lung cancer patients did report feeling no blame from others more often when compared to younger lung cancer patients in the study and that others viewed their illness as attributable to their smoking (i.e., a controllable behavior), even if a patient was never a smoker.

Faller et al. (1995) used attribution theory to explain that lung cancer patients typically attribute the cause of their disease to smoking, implying self-blame and initiating a search for ways to reduce cognitive dissonance (i.e., Lung cancer patients see that they are to blame for their illness due to their smoking behavior, yet they can readily identify other causes for their illness as well, placing less of the blame on themselves and reducing dissonance.). For example, although 70\% (when interviewed; 63\% reported via questionnaire) of the lung cancer patients in the study sample identified smoking 
cigarettes as a cause (implying their own behavior was to blame), $41 \%$ of the sample stated that the cause of their lung cancer was not known, suggesting that the placement of causal attribution on uncertainty is a method of dissonance reduction. Although this theory seems promising in predicting psychosocial adjustment to lung cancer from causal attributions, there is little research with adequate sample sizes and quantitative measures validated on samples of lung cancer patients to test the assumptions of this theory in lung cancer populations.

Besides attribution theory, Modified Labeling Theory guided an investigation of the relationship between stigma and depression in a sample of lung cancer patients (Gonzalez \& Jacobsen, 2010). The theory predicts that lung cancer patients tend to blame themselves for their cancer because society has linked lung cancer so strongly with tobacco use, which is a controllable behavior. Therefore, self-blame predicts depression in lung cancer patients.

In the development of the CLCSS, Cataldo et al. (2011) applied a model of health-related stigma to conceptualize the effects of social attitudes towards lung cancer and perception of personal identity as a lung cancer patient, which leads to negative physical and emotional reactions as well as a restructured worldview. This relationship is mediated by the lung cancer patient's awareness of aspects of stigmatization, which may include social disqualification, limited opportunities, and negative change in identity.

Other studies did not report a theoretical orientation. These studies appeared to be exploratory. Studies were either qualitative investigations of experiences of lung cancer patients (Chapple et al., 2004) or studies guided by previous findings in the literature (LoConte et al., 2008). 


\section{Summary of Psychosocial Needs, Interventions, and Barriers to Engage in Interventions}

Overall, the available literature indicates that lung cancer patients generally have high levels of need for relief from depression, anxiety, and psychosocial distress. The use of scales with cutoffs for clinically relevant levels of symptom severity for those constructs have helped to establish how great the level of those psychosocial needs is. Although it is evident that lung cancer patients have psychosocial needs related to different psychosocial and physical issues, it can be difficult for literature reviews to characterize how high the levels of those needs are and how they relate to study variables due to the use of different measurements across studies, a large diversity theories or lack thereof to guide investigations, the absence of criteria for clinically relevant levels of a given construct as measured by scales, and findings that conflict or are not replicated across studies.

Although it is evident that QoL issues, stigma, self-blame, and smoking behavior also represent domains of psychosocial needs for lung cancer patients, it is unclear how high the level of needs is due to high heterogeneity of measurements used across studies, and the lack of clear cutoffs or criteria for clinically significant levels of a given construct. Future studies should be conducted to determine criteria for low, moderate, and high levels of these constructs to facilitate the quantification of clinically significant levels of specific constructs in lung cancer patients. 


\section{Lung Cancer Patients' Experience of Psychosocial Needs}

Based on current literature regarding psychosocial needs of lung cancer patients, there is not a clear understanding of the etiology of lung cancer patients' needs, the predictors of higher levels of needs in a given psychosocial domain (e.g., predictors of depression), and what psychosocial needs lung cancer patients consider to be most important to them. Despite the available results from independent investigations, it is unclear as to the development of specific psychosocial needs of lung cancer patients due to the use of multiple theories within the same domain of psychosocial need as well as methodological shortcomings that often limit interpretations of study findings.

The results found in psychosocial literature on lung cancer research are often undermined by small sample sizes, the use of different measurements and conceptualizations of the sane construct, and the use of different or no theoretical orientations. These shortcomings limit the generalizability of findings across studies, resulting in no clear model, or theory as to the development of any one domain of psychosocial needs in lung cancer. Further complicating the integration of the findings between studies is the lack of use of procedures to control for Type I error. Few studies reported the use of such techniques like the Bonferroni correction (Naughton et al., 2002) to lower the probability that spurious findings will be reported as significant. Altogether, findings from investigations of psychosocial needs of lung cancer patients are presented with few clear conclusions that can be drawn when one reviews the available literature.

Qualitative studies are certainly more numerous in the psychosocial cluster of stigma, personal blame, and shame in lung cancer patients, which may help explain how investigations in this domain are set in the context of theories (e.g., attribution theory) 
more often than other investigations within other domains of psychosocial needs in lung cancer patients. Certainly, it seems that early studies by Faller et al. (1995) and Menec and Perry (1995) helped establish the use of theories in investigations of stigma and selfblame, which later studies by Cataldo et al. (2011) and Gonzalez and Jacobsen (2010) continued. Future studies that utilize a qualitative methodology to gather and analyze interview data may be beneficial to help elucidate the experience of lung cancer patients who have high levels of various domains of psychosocial needs.

\section{Lung Cancer Patients' Levels of Interest in Psychosocial Services}

Little is known about lung cancer patients' levels of interest in specific types of psychosocial interventions and what factors predict interest levels. There is limited evidence currently available that points to a majority of lung cancer patients in a study sample who desire information about their disease and its treatment as well as exerciserelated information and support (Sanders et al., 2010). Low response rates from eligible lung cancer patients may reflect several possible conclusions, such as a low interest in the type of service or how it is delivered. A qualitative study of lung cancer patients' perspectives regarding the preferred characteristics of psychosocial interventions may be necessary to formulate hypotheses as to the reasons why low response rates are observed in lung cancer-specific psychosocial interventions.

\section{Barriers to Engage in Psychosocial Interventions}

Across intervention studies involving lung cancer samples, there is generally low response rates may indicate that there are significant barriers to engage in psychosocial 
interventions. However, little research has been conducted to investigate this possibility.

Evidence is only available for barriers to access and engage in smoking cessation interventions for smokers (Roddy et al., 2006) and for demonstrating a potential barrier in significant discrepancies between perspectives of lung cancer patients and those who facilitate supportive care services (Devitt et al., 2010). Overall, specific evidence that elucidates the experience of lung cancer patients' troubles in accessing psychosocial interventions is lacking. This gap in the literature may be filled by a qualitative investigation involving a sample of lung cancer patients and utilizing a grounded theory approach, similar to the investigation conducted to explore smokers' perspective regarding barriers to access and maintain engagement in a smoking cessation intervention (Roddy et al., 2006).

\section{Developing Effective Interventions: The PRECEDE-PROCEED}

\section{Model}

The PRECEDE-PROCEED model of intervention development will be utilized as the context by which the proposed study will take place. It was chosen because it considers a subjective assessment of the experience of the target population (i.e., the individuals for whom an intervention's effect is intended) as the first phase of a multistep process of developing effective interventions. Since the literature is lacking on perspectives of lung cancer patients regarding how they experience psychosocial issues, what psychosocial interventions interest them, and what barriers they perceive as impeding their engagement in available interventions, a model that incorporates an 
assessment of the target population's perception of their needs as a part of developing effective interventions was an ideal framework in which the proposed study could be set.

The PRECEDE-PROCEED model has been used as a framework for building effective psychosocial interventions (Green \& Kreuter, 1999). The PRECEDEPROCEED Model of health promotion planning is considered "a theoretically 'robust' model that addresses a major acknowledged need in health promotion and health education: comprehensive planning" (pp. 35-36). Numerous health departments, randomized clinical trials, and other health projects have implemented PRECEDEPROCEED. Also, a variation of the PRECEDE-PROCEED model has been recommended by the American Lung Association as a Program Planning and Evaluation Guide for Lung Associations (L. W. Green, 1987). A brief description of the first two phases of the model will illuminate a weakness that exists within the process of development, implementation, and evaluation of psychosocial interventions that target the population of lung cancer patients: Interventions are too often implemented without a continuous subjective needs assessment of the participants involved. Indeed, Green and Kreuter (1999) state that two foundational pieces of information for sound intervention development are the subjective needs and the health problems of the target population.

Phase one and phase two of the PRECEDE-PROCEED model address the subjective concerns of the target population (phase one) and allow those to inform the ranking of relevant threats to health (phase two; Green \& Kreuter, 1999). Although it may be necessary for some health care professionals to develop programs without the benefit of enough time or resources to begin an intervention assessment through subjective evaluation by the target population, the concerns of patients should be a vital 
resource to help inform the dynamic growth of such programs throughout every phase. Without the guide provided by the views of lung cancer patients, psychosocial interventions may develop a myopic understanding of the entire context of health needs (medical and psychological) that are most pressing in their minds. In her editorial concerning the use of theory in health promotion, Green (2000) warned of the danger inherent when health promotions are completely guided by amassing empirical data on the effectiveness of given interventions. She argued, "Of more relevance to the practitioner are general principles together with an understanding of context-specific factors, which will allow adaptation to suit different situations" (p. 129). She posited that the inclusion of such factors in the design and implementation of interventions would help avoid "type III error," which is defined as "the rejection of the effectiveness of a programme when the programme itself was inadequate in terms of design or delivery" ( $\mathrm{p}$. 126). Essentially, attention must not only be placed upon the evaluation methodology, but care is to also be taken in the development of quality psychosocial interventions.

In the case of lung cancer patients, it is then of great importance to ascertain which psychosocial interventions they would consider most helpful. It is apparent that investigators are delivering interventions that are either of little interest to lung cancer patients or are delivered without regard to barriers that the target population perceives. In light of the call for psychosocial interventions that are contextually relevant and theoretically grounded, an assessment of the unique psychosocial needs of lung cancer patients is necessary and has begun with such investigations by Sanders et al. (2010) and Devitt et al. (2010). 


\section{The Importance of the Target Population's Perspective in Current \\ Lung Cancer Intervention Development}

Carlsen and colleagues (2005) have discussed that lung cancer patients may benefit from tailored interventions, which are specific to the socio-cultural context of the target population (p. 299). Interventions that are constructed to mesh with the unique backgrounds of diverse patient populations must be guided by subjective needs assessments because different patient populations inevitably comprise different composites of individual cultural backgrounds. As the PRECEDE-PROCEED model suggests, the development of effective psychosocial interventions for lung cancer patients must begin with an understanding of the needs that they consider to be most important. As Carlsen and colleagues (2005) suggest, this may be accomplished through standard psychosocial screening of lung cancer patients, which can provide a clearer picture of which psychosocial interventions may prove to be most beneficial or should be offered. Although Carlsen and colleagues (2005) make this suggestion for the purpose of identifying lung cancer patients who are depressed and are at risk for depression, a comprehensive psychosocial screening instrument can help identify an array of needs that can be met with the appropriate intervention (Taenzer et al., 2000). This scenario (i.e., using a standard psychosocial screening instrument) may prove beneficial in healthcare settings that already possess a wide array of available psychosocial services for cancer patients. However, if novel psychosocial interventions need to be developed, then it would be beneficial to conduct a subjective needs assessment, which can be comprised of qualitative methods to capture in-depth patient perspectives. If a psychosocial intervention is guided by the goal of meeting those pertinent needs, then the intervention 
will be more likely to demonstrate a higher level of effectiveness or efficacy, depending on the setting of the intervention.

\section{Study Aims}

The study addressed the following three aims, which are stated as research questions (Strauss \& Corbin, 1998): 1) Which psychosocial needs do lung cancer patients consider to be the most important, 2) what are the barriers that lung cancer patients perceive as hindering them to engage in a psychosocial intervention, and 3) which methods of delivering psychosocial interventions are most desired by lung cancer patients? Since these questions address a poorly understood domain of the research literature, and the focus of the study was rooted in the concerns (or perspectives) of the subjects (Strauss \& Corbin, 1998); the study utilized qualitative methodology - guided by a grounded theory design - to explore how lung cancer patients perceive their psychosocial needs, the psychosocial interventions that are available to them, and the barriers that impede accessing and maintaining engagement in interventions.

\section{Study Design}

In an attempt to understand the psychosocial needs of lung cancer patients and how healthcare professionals can meet those needs, a qualitative design guided the research process for this study (Strauss \& Corbin, 1998). Akin to other studies that utilized a grounded theory approach (e.g., Badr \& Taylor, 2006), the study analyzed the qualitative data gathered with the goal of deriving an explanation that addressed the aims

of the study. Since grounded theory (GT) designs have been utilized to compose a theory 
of processes common across the subjects involved in the study (Creswell et al., 2007), the proposed study implemented a GT design to elucidate shared phenomena across the lung cancer patients that will be included in the study.

The GT approach was implemented to guide the investigator towards a theory that will emerge from the qualitative data. As grounded theory is an approach that begins with the collection of data, which is then followed by immersion into the data and the subsequent emergence of theory, Strauss and Corbin (1998) describe the proper approach to carrying out studies that implement a grounded theory design.

Using the grounded theory approach to analyze the qualitative data, it was imperative for the investigators to examine the subjects' responses without projecting personal perceptions or biases regarding the actual content of the responses or the theory that will be built at the conclusion of the study. Although they admit that absolute objectivity is impossible, Strauss and Corbin (1998) emphasized the importance of objectivity during a qualitative analysis of the data, especially within a study that is guided by the grounded theory design. When focusing on the concerns of the subject, it was crucial to design and deliver the interview schedule from a neutral orientation, which is not influenced by heuristic knowledge or expectations regarding the theory that will emerge. If an investigator approached the data with biases (e.g., about the nature of the subjects or the theory that is expected to emerge) that influence the development of the interview schedule and interactions with the subjects, then it would be likely that the emergent theory will not accurately reflect the perspective of the subjects. With the importance of objectivity in viewing the data at the forefront of the investigator's concern, the study was approached with a GT design. 


\section{CHAPTER TWO \\ METHOD}

\section{Subjects}

Since the theoretical population for this study will be lung cancer patients in the USA, a sample of lung cancer patients was recruited from the accessible population of lung cancer patients who were registered in the Loma Linda University Medical Center (LLUMC) cancer registry (i.e., the sampling frame). The investigators decided to sample from the LLUMC cancer registry because the lung cancer patients who are found in the cancer registry are thought to be representative of lung cancer patients treated at cancer centers throughout the United States.

The investigator aimed to recruit a sample of 20-30 lung cancer patients for the study. This number of subjects matched the number provided within the example of a grounded theory-guided study in Creswell and colleagues' (2007) overview of qualitative research designs. At this number of subjects, the emergent theory should be saturated with qualitative data such that further data collection from additional lung cancer patients would provide no more substantive or unique information about the perspective of lung cancer patients in the LLUMC cancer registry.

\section{Sampling Strategy}

After screening the LLUMC cancer registry for patients with lung cancer, the manager of cancer outcomes and quality at the Loma Linda University Cancer Center (LLUCC) emailed only the portion of the registry that includes outpatient cases, inpatient cases, and emergency visits of cancer patients diagnosed with lung cancer on a monthly 
basis. The investigator selected those patients who have not already been included in an IRB-approved ongoing study of psychosocial adjustment to lung cancer (see Sanders et al., 2010) and requested contact information (i.e., phone number(s) and mailing address) for those selected patients through the manager of cancer outcomes and quality. Once the contact information was obtained, the investigator called the lung cancer patients and requested their consent to participate in the ongoing study via telephone.

The inclusion criteria of the proposed study included the following: 1) a diagnosis of lung cancer, 2) completion of the baseline questionnaire of the ongoing study, 3) the ability to understand written and verbal English, 4) the ability to speak in English, 5) an indication that the subject would be interested in participating in future research (determined by the subject's response to an item in the baseline questionnaire of the ongoing study), 6) the expressed verbal consent from the subject, and 7) the completion of the entire interview schedule. Individuals were excluded from the study if they did not meet all of the inclusion criteria.

It was expected that the sample recruited for the proposed study would closely resemble the demographics found in the study conducted by Sanders and colleagues (2010) because both studies indicate that the sample is selected from accessible populations from hospitals in southern California, one of which is from the same hospital (LLUMC). If demographic characteristics of the sample did not change significantly since the study by Sanders and colleagues (2010), then it was expected that the sample of lung cancer patients in the proposed study were typically be older $(M=68.5$ years, $S D=$ 10.1 years), about evenly distributed between sexes, had an education almost at the high school level ( $M=13.5$ years, $S D=2.6$ years), mostly composed of Caucasian subjects 
(77.4\%), had a little over a year's time lapse since initial diagnosis $(M=54.1$ weeks, $S D$ $=63.6$ ), and would typically be diagnosed at a later stage (stages III \& IV: 44.8\%; stages I \& II: 24.7\%; stage unknown: 30.5\%). In the proposed study, demographic characteristics regarding the subjects' age, sex, years of education, ethnicity, time since diagnosis, type of lung cancer, and stage of disease were reported.

It is also important to consider that subjects included in the proposed study were considered by Rosenthal and Rosnow (2008) to be "second-level volunteers" (i.e., The sample recruited for the proposed study consisted of a sample from the "volunteers" in the ongoing study.). Therefore, it was important to compare the demographics of those who agree to participate in the proposed study to those who were eligible to participate but choose not to be interviewed for the proposed study. That comparison demonstrated whether the sample of lung cancer patients in the proposed study represents a biased sample compared to those who were eligible but did not participate. Specifically, chisquare (for tests involving categorical variables) and $t$-tests (for tests comparing continuous variables) comparing demographic information between the those who opted not to participate in the proposed study (despite being eligible) and those who completed the interviews informed the investigator whether the study sample was externally valid to the available population of lung cancer patients.

\section{Study Setting and Materials}

The proposed study was conducted in the Behavioral Oncology Laboratory (BOL) at Loma Linda University. Specifically, all telephone calls to eligible participants, storage of recorded interviews, transcriptions of interviews, and qualitative analysis of 
the interview data took place in the BOL. The BOL was considered secure because two separate keys for two different doors were required to access the laboratory.

\section{Interviews}

The interviews were recorded via a digital recorder, which were connected directly to the telephone line. During the administration of the interview, the investigator referred to an interview protocol (see Appendix) to standardize the interview format. Recordings captured words from both the investigator as well as the participant. Since the recorder was outfitted with a built-in USB interface, each recorded interview was downloaded and saved onto Apple i-Tunes software to be played back for the purpose of transcribing the interview verbatim. Transcriptions were be typed and saved onto Microsoft Word documents to facilitate the printing of the multiple copies necessary for a qualitative analysis (Strauss \& Corbin, 1998). All hardcopies of the transcripts were stored in a file cabinet within the Behavioral Oncology Laboratory (BOL). All recordings of the interviews were saved on a password-protected hard drive. At the conclusion of the study, the saved recordings were erased from the hard drive; and no copies of the interviews were retained (in either paper or digital format).

\section{Interview Protocol}

The interview protocol included a script that the investigator used to greet the participant, inform the participant about the purpose of the interview, and conduct the recorded interview (see Appendix). The interview protocol contained separate scripts depending on patient responses to questions regarding participation (e.g., If the patient 
responds with "Yes," then reply...") as well as a script for calls made on the day of a scheduled interview (i.e., If a participant wishes to reschedule the interview, a different script is provided to the investigator to use for such a call.).

The interview schedule was in a semistructured format; qualitative data was gathered from participants' responses to open-ended questions (e.g., "When you think about it, what types of needs do you usually require help with?") and fixed questions (e.g., "On a scale from one to ten, one being little to no interest and ten being extremely interested, what is your level of interest in the following ways of meeting your needs..."). A list of recommended probes appeared at the bottom of the interview schedule to query for more information about a response. The semistructured format was chosen to allow for variability in individual responses and to facilitate a standard method of administering the recorded interview. The content of the questions included in the interview schedule were generated to address the three aims of the proposed study. Specifically, the first three sections of the interview schedule (see Appendix) addressed the three aims of the study, and sections 4 and 5 are supplemental to qualitative data from the three previous sections.

\section{Procedure}

A flowchart of the recruitment of participants over the course of the current study can be viewed in Figure 1. Investigators attempted to recruit lung cancer patients who have completed the baseline questionnaire of the ongoing study in a two-step process: 1) An envelope containing a consent sheet and a letter explaining that a researcher will be 


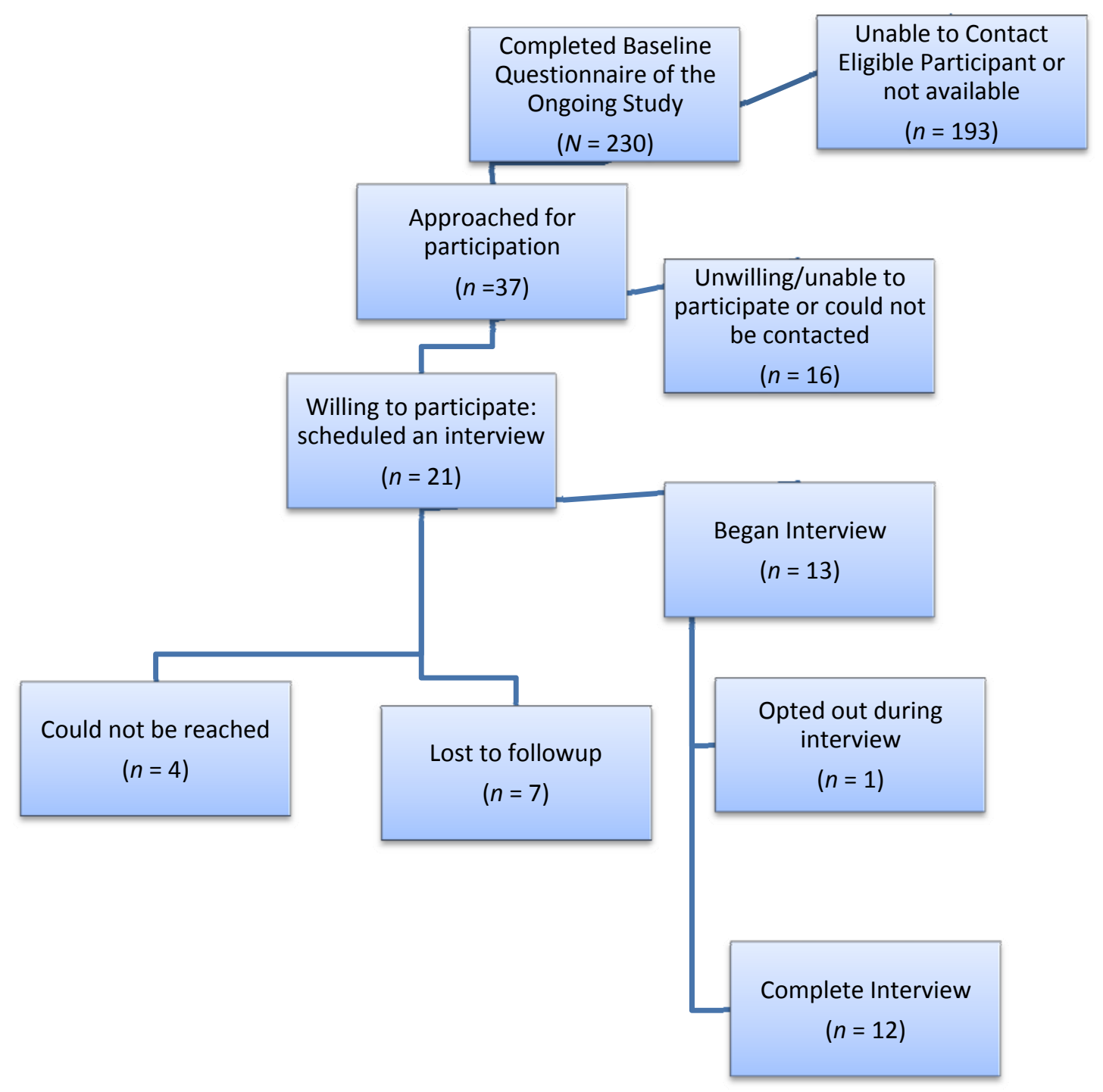

Figure 1. Flowchart of recruitment and attrition in the current study.

calling within the next two weeks will be mailed to the potential participant, and 2) an investigator will call the potential participant within two weeks.

After sending the letter to the potential participant, an investigator attempted to contact him/her by telephone. If the lung cancer patient answered the call, then the investigator determined whether he/she is willing and able to participate in the proposed 
study. However, if the patient did not answer the call, two more attempts were made to contact the potential subject before his/her name will be dropped from the list of eligible participants to contact. Also, if a participant wished to opt out of the proposed study, he/she was not contacted again regarding participation in the proposed study.

If the participant was willing to participate yet needed to reschedule the interview for a later date, then the investigator asked for another time that will work for interviewing the patient. The investigator then contacted the participant on the desired day and time that was mutually agreed upon by both the investigator and the participant. If the patient was no longer willing or able to participate in the proposed study, then the investigator no longer contacted him/her.

Before the interview was conducted, participants were reminded that they have the option to opt out of the interview and end their interview session at any time. Recordings of any interview sessions in which the patient opted out in the middle of the interview was immediately erased and not used in the qualitative analysis of the data.

When the interview was conducted, a semistructured interview format was utilized to provide some standardization of responses directed towards the aims of the proposed study. However, some flexibility was provided in patient responses by openended questions to explore the perspective of the population, which may have been missed if more fixed questions were asked.

Just prior to beginning the interview, the investigator was cued by the interview protocol to begin recording the interview. A digital recorder recorded the two-way discourse between the investigator and the patient. The recorder was connected directly to the telephone line to capture the entire interview. After the interview was complete, 
the investigator was cued by the interview protocol to stop the recording of the telephone conversation between the researcher and the patient.

Utilizing the built-in USB interface of the digital recorder, the investigator downloaded the audio recording data onto Apple i-Tunes in .mp4 format. Each separate participant's recording was saved onto different audio files, using their identification numbers from the ongoing study (i.e., the same identification number that appears on the baseline questionnaire they completed in the ongoing study) to indicate which recording belonged to a given participant. Once the audio recordings were saved onto i-Tunes, the investigator played them back through headphones and transcribed them onto Microsoft Word documents. The patients' identification numbers from the ongoing study was also used in the names of the saved Word documents. All digital recordings and Word documents pertaining to the proposed study were saved onto a password-protected hard drive in the BOL. The transcriptions of the recordings were printed for the purpose of a qualitative analysis of the interviews. All printed transcriptions were kept within a file cabinet within the BOL.

Also, demographic information from the baseline questionnaire of the ongoing study were used in a quantitative analysis. The IBM Statistical Package for the Social Sciences version 19 (SPSS) was utilized in the quantitative analysis portion of the proposed study.

At the conclusion of the current study, all digital audio recordings and transcription files saved onto the password-protected hard drive were erased. Also, all printed transcriptions of the interviews were destroyed at the current study's completion. 


\section{Demographic Information}

A questionnaire was used to assess sex, age, education level, level of income, lung cancer type, stage of cancer, time since diagnosis, and smoking status.

\section{Supportive Care Needs Survey (SCNS)}

The SCNS is a 31-item measurement of the level of perceived need, which uses a five-point Likert scale that ranges from 1-5. The range of scores for each individual item can be split between the 1-2 range as having no need for the item (1 = "not applicable" and $2=$ "satisfied") and the 3-5 range as having some level of need represented by the item ( 3 = "low need," 4 = "moderate need," and $5=$ "high need"). The overarching factor (Total Supportive Care Needs [TSCN]) was used. This scale has been shown to be a reliable instrument when used in samples of cancer patients (Li \& Girgis, 2006; Sanders et al., 2010). The internal consistency of this measure was acceptable in the current study, $\alpha=.79$.

\section{Data Analysis}

Analysis of the data obtained for the proposed study involved quantitative and qualitative data: 1) Analysis of quantitative data obtained from the information provided in the baseline questionnaires of the ongoing study and 2) analysis of qualitative data from the interviews. 


\section{Quantitative Data Analysis}

The purpose of the quantitative analysis portion of the proposed study was to determine whether selection of participants were biased based on demographic characteristics and total supportive care needs (TSCN). If the study sample was not significantly different across demographic characteristics and TSCN when compared to eligible patients, then it was assumed that the selection of participants was not biased. However, if significant differences in demographic characteristics were found, then the results of the qualitative analysis would be interpreted with caution, and it would be noted that the results from the qualitative analysis might be unique to the sample of patients who participated in the study.

Demographic characteristics that were included in the analyses are the following variables: sex (male or female), age, ethnicity (Caucasian or other ethnicity), weeks since diagnosis, type of cancer (non-small cell, small cell, or not sure), and stage of cancer (Stages I, II, III, IV, or not sure). Chi-square analyses were used to test for differences between the patient who completed interviews and those who were eligible and opted out of the study or could not be contacted on categorical demographic variables (i.e., sex, ethnicity, type of cancer, and stage of cancer). Continuous demographic variables were assessed by one-sample $t$-tests, using the means from the larger sample of lung cancer patients as the theoretical averages of the population (i.e., age, weeks since diagnosis, education, and TCSN). The significance level was set at $\alpha=.05$. 


\section{Qualitative Data Analysis}

An outline of the method used to analyze the qualitative data is shown in Figure 2 (p. 45). The analysis of the interview data was guided by a GT design, specifically utilizing the methodology from Strauss and Corbin's Basics of Qualitative Research: Techniques and Procedures for Developing Grounded Theory (1998). Since the current study addressed three aims, qualitative data gathered from sections 1,2 , and 3 from the interview schedule (see Appendix) will be analyzed separately to directly address each separate aim. Responses from section 4 of the interview schedule was considered supplemental data to section 2 because it may provide additional data regarding lung cancer patients' preferences for psychosocial interventions. Any data from section 5 of the interview (i.e., "Are there any other things that you would like to mention before we end the interview?") was only considered supplemental data to answer the three aims of the proposed study if it was considered relevant and was apparent how the response related to a given study aim.

First, a qualitative analysis of the interview transcripts began with a line-by-line analysis of the content of the patient responses to queries from the interview. Categories (i.e., phenomena) were conceptualized during this sequential analysis and were informed by the context of the response content around each phenomenon identified as well as by the context of the patient (e.g., adjusting to the treatment and diagnosis of lung cancer). 


\section{Step 1: Line-by line analysis}

Initial concepts and phenomena were formed

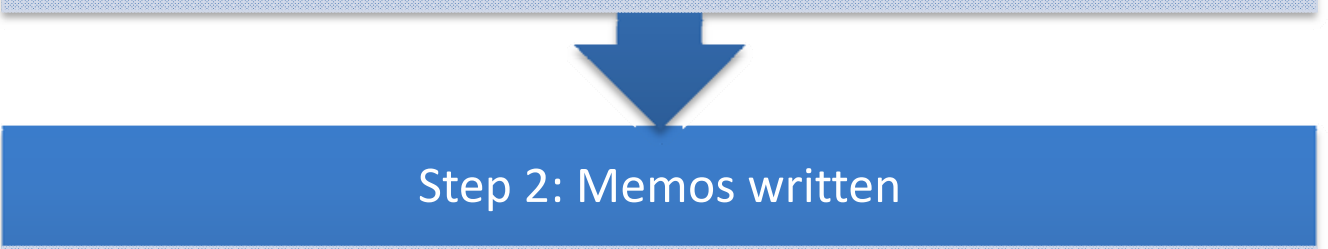

Range of potential meanings of initial concepts informed the labeling of phenomena

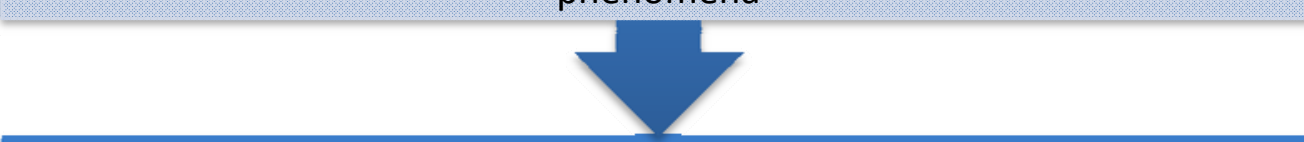

\section{Step 3: Labeled phenomena were reviewed}

Concepts were consolidated into broader or more abstract phenomena

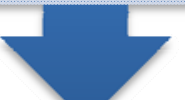

\section{Step 4: Axial coding}

Concepts were refined according to commonly expressed dimensions or properties of that phenomena

\section{Step 5: An experienced qualitative investigator independently reviewed} identified phenomena

Agreement between reviewers determined the final set of categories

Figure 2. Process of qualitative data analysis used in the current study.

Second, the transcripts were reviewed again for the purpose of recording memos regarding the range of potential meanings within the responses given by the patients. The investigator specifically commented on the potential meanings of the responses as they related to the categories identified in the line-by-line analysis of the transcripts. Once 
memos were recorded for each transcript, phenomena were labeled according to themes that were shared across the patient's responses.

Third, the accumulated concepts (i.e., phenomena) were reviewed for the purpose of consolidating phenomena that may be grouped under a broader concept. Grouping of related concepts occurred in one of two ways: 1) Two or more concepts related to each other under a single category (e.g., Difficulty driving and difficulty taking public transportation to a site of treatment can be categorized under a "Transportation Barrier" phenomenon.), or 2) more abstraction was be necessary to consolidate a high number of phenomena from the line-by-line analysis and memos (e.g., five or more categories relate to the abstract concept of "Financial Problems").

Fourth, axial coding was used to determine whether certain properties or dimensions of identified phenomena could be grouped to form concepts. For example, if the content of patient responses that formed a category involved a commonly expressed dimension, then that property would be included in the label of the phenomenon.

Fifth, the identified concepts (i.e., phenomena) were used to assess inter-rater reliability. An experienced qualitative investigator independently assessed how the identified concepts are expressed within the content of the patient responses. Specifically, the qualitative investigator determined which phrases or sentences indicated the identified phenomena and whether additional or fewer categories were necessary. Discrepancies amongst the panel were resolved in a group meeting in which the final group of identified phenomena was decided. 


\section{CHAPTER THREE}

\section{RESULTS}

\section{Characteristics of the Study Sample}

Out of 230 lung cancer patients who completed the baseline survey of the ongoing study, $37(16.09 \%)$ were approached for participation in the study. Out of those who were approached, $3(8.11 \%)$ were deceased, $21(56.76 \%)$ were contacted to schedule an interview, and 17 (45.95\%) scheduled an interview. Of those who scheduled an interview, $4(23.53 \%)$ could not be reached for the follow-up interview and $1(5.88 \%)$ opted out of the study. The study sample was composed of 12 lung cancer patients who completed interviews (see Figure 1).

Table 1 (p. 48) shows the demographic characteristics of the study sample in comparison to the larger sample that completed at least one baseline survey. Chi-square and one-sample $t$-tests demonstrated that the patients that were interviewed did not significantly differ from the larger sample by sex, age, ethnicity, education, lung cancer type, stage of cancer, weeks since first diagnosed, and Total Supportive Care Needs. The study sample $(n=12)$ was composed mostly of non-Hispanic white $(91.7 \%)$, female (58.3\%) patients who were typically diagnosed with non-small cell lung cancer $(72.7 \%)$ and were uncertain of the progression of their cancer (41.7\%). Although participants were diagnosed less often at stages III (8.3\%) and IV (16.7\%) compared to the larger reference group (18.5\% and 30.8\% diagnosed at stages III and IV, respectively), the difference was not significant. They were elderly $(M=68.33$ years, $S D=7.75$ years $)$ but younger than the median age (71 years) for individuals with lung cancer between 
Table 1

Demographic and Medical Characteristics of the Study and Reference Samples.

\begin{tabular}{|c|c|c|}
\hline & $\begin{array}{c}\text { Study Sample } \\
\quad(N=12)\end{array}$ & $\begin{array}{l}\text { Reference Sample } \\
\quad(N=230)\end{array}$ \\
\hline Variable & $n(\%)$ & $n(\%)$ \\
\hline \multicolumn{3}{|l|}{ Sex } \\
\hline Male & $5(41.7 \%)$ & $94(43.1 \%)$ \\
\hline Female & $7(58.3 \%)$ & $124(56.9 \%)$ \\
\hline \multicolumn{3}{|l|}{ Ethnicity } \\
\hline White & $11(91.7 \%)$ & $169(80.1 \%)$ \\
\hline Other & $1(8.3 \%)$ & $42(19.9 \%)$ \\
\hline \multicolumn{3}{|l|}{ Type of lung cancer } \\
\hline Non-small cell & $8(72.7 \%)$ & $107(56.3 \%)$ \\
\hline Small cell & $2(18.2 \%)$ & $53(27.9 \%)$ \\
\hline Other & $0(0 \%)$ & $28(14.7 \%)$ \\
\hline Don’t know & $1(9.1 \%)$ & $2(1.1 \%)$ \\
\hline \multicolumn{3}{|l|}{ Stage of cancer } \\
\hline I & $1(8.3 \%)$ & $31(14.7 \%)$ \\
\hline II & $3(25.0 \%)$ & $18(8.5 \%)$ \\
\hline III & $1(8.3 \%)$ & $39(18.5 \%)$ \\
\hline IV & $2(16.7 \%)$ & $65(30.8 \%)$ \\
\hline \multirow[t]{2}{*}{ Don't know } & $5(41.7 \%)$ & $58(27.5 \%)$ \\
\hline & $M(S D)$ & $M(S D)$ \\
\hline Age & $68.33(7.75)$ & $66.95(10.64)$ \\
\hline Education & $12.67(2.71)$ & $13.48(2.69)$ \\
\hline $\begin{array}{l}\text { Weeks since first } \\
\text { diagnosed }\end{array}$ & $72.83(108.00)$ & $51.14(72.96)$ \\
\hline Total supportive care needs & $2.34(0.70)$ & $2.54(0.73)$ \\
\hline
\end{tabular}

Note. Discrepancy from the total sample of the Reference Group $(N=230)$ and totals for each category due to missing data within those categories.

2004-2008 in the United States (SEER; Howlader et al., 2012). Time since their initial diagnosis varied greatly from an average of about 18 months $(M=72.83$ weeks, $S D=$ 108.00 weeks). Total supportive care needs were between the level of "met need" and "low need" $(M=2.34, S D=0.70)$. 


\section{Findings from the Interviews}

From the 12 interviews that were included in the study, emergent themes and categories were recorded in a codebook. Themes were organized according to each aim of the current study: 1) determining the most pertinent psychosocial needs of lung cancer patients, 2) describing perceived barriers in meeting their needs, and 3) evaluating their level of interest for different methods of delivering psychosocial interventions. Three themes emerged under the first aim (No Current Psychosocial Need, Physical and Medical Needs, Current Psychosocial Needs), six themes emerged under the second aim (Time Constraint, Limited Income, Travel, Lack of Information, Anxiety, Limited Motivation/Necessity), and different numbers of categories emerged under the five themes (Internet, Face-to-Face, Support Group, Telephone, Personal Effort) of each intervention method explored during the interview. All transcripts were double-coded and checked for inter-rater reliability. Consistency between raters was considered acceptable, kappa $=0.84$.

\section{The Most Pertinent Psychosocial Issues of Lung Cancer Patients}

When asked about their needs beyond just medical care, almost half (41.7\%) of the study participants indicated that they either never had any psychosocial need or did not currently have a need. However, by the end of the interview, every participant mentioned at least one category pertaining to a specific psychosocial need. Also, specific physical and medical needs were reported by more than half $(66.7 \%)$ of the study sample. Figure 3 (p. 50) shows each category of psychosocial need that was reported. 


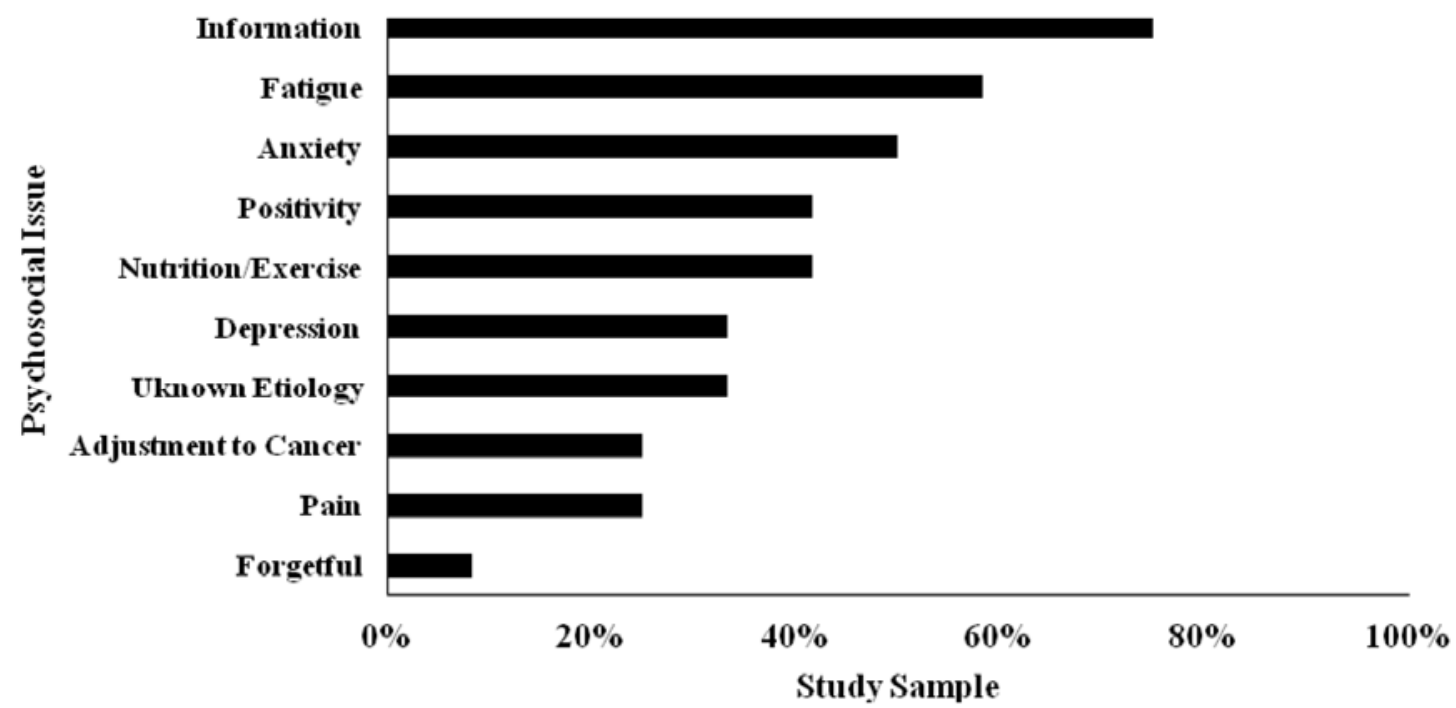

Figure 3. Frequency of psychosocial issues reported by the study sample.

Psychosocial issues that were reported by half or more of the interviewed lung cancer patients were disease and treatment-related information $(75.0 \%)$, fatigue $(58.3 \%)$, and anxiety about future medical exam results or cancer recurrence (50.0\%). Almost one-half $(41.7 \%)$ of the patients stated that staying positive or seeking the positive in their situation was important (e.g., "It's a good thing for people who have cancer to have a positive perspective."). The same percentage of participants reported that nutrition or exercise-related information and support was important to them. One-third of the study sample $(n=4)$ reported depressed mood (e.g., "I guess I depress once in a while when I think about my cancer.") and difficulty understanding the underlying cause of specific symptoms (e.g., "I guess right now we'll be limbo again until we determine what is the cause of the symptoms I'm having."). One-quarter of the participants $(n=3)$ indicated that pain sensations and adjusting to life with cancer (e.g., "Is this life going to be forever like this? Okay, I'm living, but it has got a lot of restrictions.") were problematic. Most 
participants $(75 \%)$ indicated that they utilized some strategy to address their psychosocial need, which included spiritual (e.g., "I pray a lot."), family and friends (e.g., "Well, like I have mentioned before I have a very nice circle of friends. During those periods of time, I had a lot of support from them."), professional support (e.g., "Well, I'm in physical therapy for pulmonary cardio therapy."), and personal effort (e.g., "I do most everything for myself.") strategies.

\section{Barriers that Hinder Engagement in Psychosocial Interventions}

Except for one lung cancer patient, participants perceived at least one barrier that might hinder meeting their psychosocial needs. Descriptions and examples of the emergent themes of barriers are displayed in Table 2 (p. 52).

Barriers related to the theme of Time were reported most frequently $(n=6$, $50.0 \%$ ), which involved being busy and having difficulty with scheduling times that would work for the patient. Almost one-half (41.7\%) of the participants stated that categories related to the theme of Travel (i.e., travel expense, inability to drive, long distance) were barriers to meeting their psychosocial needs. One-third $(n=4)$ perceived that Finance/Income problems and limited Necessity/Motivation served as barriers. Two participants (16.7\%) reported that categories related to the theme of Anxiety (i.e., fear of cancer recurrence, not wanting to bother others for support) hindered their seeking for help. Another two patients stated that a barrier was Lacking Information about what a psychosocial intervention might entail. Barrier themes and their frequency of emergence in the study sample are displayed in Figure 4 (p. 53). 
Table 2

Emergent Theme Descriptions and Examples of Barriers to Intervention Engagement.

\begin{tabular}{|c|c|c|}
\hline Theme & Description & Interview example \\
\hline Time & $\begin{array}{l}\text { There are too many demands for one's } \\
\text { time, and it may be too difficult to } \\
\text { schedule attendance for an intervention. }\end{array}$ & $\begin{array}{l}\text { "You still got family to take } \\
\text { care of, things to do, errands } \\
\text { to run." } \\
\text { "I have to adjust my } \\
\text { scheduling to work around } \\
\text { that." }\end{array}$ \\
\hline Travel & $\begin{array}{l}\text { The process of arriving at the site where } \\
\text { the intervention takes place might be } \\
\text { problematic due to the long distance } \\
\text { from one's residence, the cost of travel, } \\
\text { or limitations in ability to drive a } \\
\text { vehicle. }\end{array}$ & $\begin{array}{l}\text { "I'm not driving because of } \\
\text { this sleepiness and other } \\
\text { problems I am having." } \\
\text { "With gas prices and things } \\
\text { like that, it's hard to go } \\
\text { anywhere anymore." } \\
\text { "I got tired of going there. It's } \\
\text { too far from me." }\end{array}$ \\
\hline Necessity/motivation & $\begin{array}{l}\text { The patient perceives that their } \\
\text { likelihood of attending an intervention } \\
\text { is directly related to their level of need } \\
\text { and motivation to engage in an } \\
\text { intervention. }\end{array}$ & $\begin{array}{l}\text { "Sometimes when I got into, } \\
\text { 'oh I think I'm going to do } \\
\text { this,' then I think about it a } \\
\text { while longer and then I don't } \\
\text { do it anymore because my } \\
\text { motivation isn't as strong as it } \\
\text { was } 2 \text { weeks before or } \\
\text { whatever." } \\
\text { "I don't feel like I need it." }\end{array}$ \\
\hline Finance/income & $\begin{array}{l}\text { The chance of attending an intervention } \\
\text { is lower due to financial burden or low } \\
\text { income. }\end{array}$ & $\begin{array}{l}\text { "When you get sick like this, } \\
\text { your bills go up and your } \\
\text { income goes down." }\end{array}$ \\
\hline Anxiety & $\begin{array}{l}\text { A manifestation of worry or anxious } \\
\text { feeling is bothersome and lowers the } \\
\text { likelihood of intervention attendance. } \\
\text { Anxious feelings might be caused by } \\
\text { fear of cancer recurrence or worry that } \\
\text { receipt of assistance will be a bother to } \\
\text { others. }\end{array}$ & $\begin{array}{l}\text { "Always in the back of my } \\
\text { mind is just how is it gonna } \\
\text { come back again and get } \\
\text { worse." } \\
\text { "I really don't want to put } \\
\text { other people... make them } \\
\text { have to run back and forth for } \\
\text { me because I don't think that } \\
\text { is fair. I don't like to bother } \\
\text { people." }\end{array}$ \\
\hline Lacking information & $\begin{array}{l}\text { Prior knowledge of an intervention, } \\
\text { such as how it is delivered and what } \\
\text { might be expected of intervention } \\
\text { attendees, affects interest. }\end{array}$ & $\begin{array}{l}\text { "My enthusiasm would } \\
\text { probably be a lot better or a lot } \\
\text { worse if I knew exactly what it } \\
\text { pertains to." }\end{array}$ \\
\hline
\end{tabular}




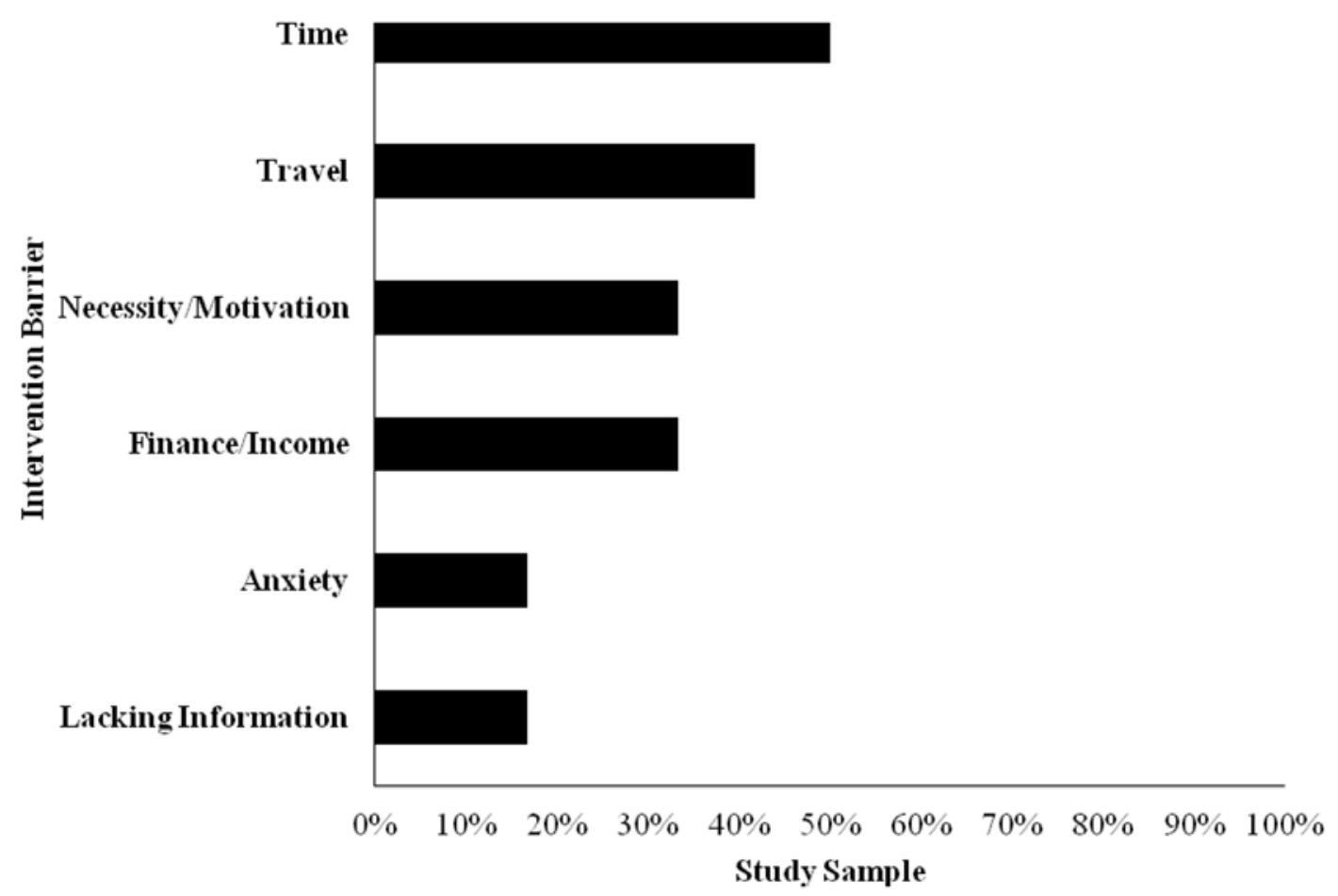

Figure 4. Frequency of barriers reported by the study sample.

\section{The Most Desired Methods of Psychosocial Intervention Delivery}

Participants were asked to rate their level of interest (using a 1-10 scale) in receiving psychosocial services through the following modalities: Internet, face-to-face, support group, telephone, and personal effort (i.e., no external support). After providing their interest rating, the interviewer asked patients for their rationale, which led to the emergence of categories under each intervention theme (i.e., mode) to help explain why individual patients might assign a certain magnitude of interest. Average interest levels for intervention methods explored in the study are shown in Figure 5 (p. 54). 


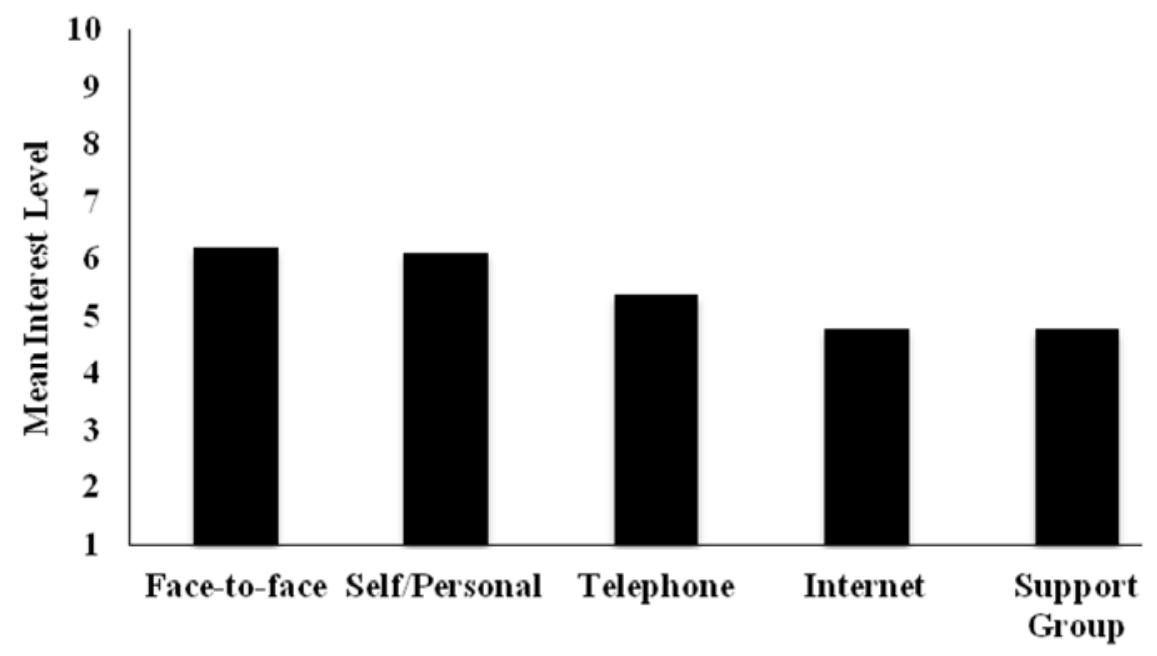

Intervention Method

Figure 5. Average interest ratings for psychosocial delivery methods.

The highest mean levels of interest were in face-to-face $(M=6.21, S D=3.50)$ and personal effort $(M=6.13, S D=2.30)$ methods of intervention. Eighty-three percent $(n=10)$ and $75 \%(n=9)$ of the participants rated their interest as a five or higher in personal effort and face-to-face methods of intervention, respectively. Participants' mean interest ratings for Internet $(M=4.79, S D=2.74)$, support group $(M=4.77, S D=3.39)$, and telephone $(M=5.38, S D=3.15)$ methods of intervention were about the middle of the 1-10 scale. Two-thirds $(n=8)$ of the participants rated the Internet and telephone at an interest level of five or higher. It should be noted that one participant could not rate his level of interest in a support group method of intervention.

\section{Internet}

Four categories emerged from the rationales provided for interest ratings regarding Internet-based psychosocial interventions: reliability, source of information, 
current usage, and limited use or no interest. One-quarter of the participants $(n=3)$ explained that the reliability of information from the Internet influenced their ratings, typically inciting caution in those participants (e.g., "Sometimes I don't know how reliable the source is."). Usually when explaining why the participant rated their interest in the Internet as a five or higher, participants $(n=4,33.3 \%)$ perceived the Internet as a source of information (e.g., "Well, the Internet helps a lot. It gives you information."). One participant (8.3\%) indicated that currently using the Internet influenced the interest rating. However, five participants $(41.7 \%)$ indicated that not using the Internet or having no interest in using the Internet explained their low interest ratings. Interviews from two of the participants provided no categories under the Internet theme.

\section{Face-to-Face}

Four categories emerged from the rationales provided for interest ratings given regarding face-to-face interventions: tailored and immediate information, nonverbal communication, trusted expert and professional support, and no interest. Two participants $(16.7 \%)$ indicated that having information that was specific (i.e., tailored to their case) and immediate from another individual was important to them (e.g., "The reasoning behind that is as you are seeing or talking about things, questions arise while you are talking. You want an answer and right then."). Three participants (25.0\%) reported that viewing an individual's nonverbal communication was important to them (e.g., "You can read a lot in the expression of a person.") and also influenced one of their ratings to be higher than telephone-based interventions (e.g., "It was easier for me to read somebody by having one-on-one contact."). One-half $(n=6)$ of the study sample 
indicated that receiving face-to-face support from an individual recognized as a trusted professional or expert was important to them (e.g., "I think I want to be one-on-one with a doctor.”). Three participants (25.0\%) reported having limited interest in receiving faceto-face support. Interviews from three participants contained no categories under the theme of face-to-face interventions.

\section{Support Group}

When participants were queried for their rationales for their interest ratings in a support group format for an intervention, seven categories emerged. The categories included timing of joining a group (i.e., does it coincide with current need or future need), having previous experience in a support group, being in a group of individuals that share common experiences (e.g., specific cancer type), hearing positive and hopeful aspects of group members' experiences, disliking hearing about stories from others in the group, desiring an expert panel (i.e., professionals or experts compose the group members to inform the patient), and no interest. Out of those categories, participants $(n=5$, 41.7\%) most frequently stated that having a group composed of members with similar experiences (e.g., having lung cancer) was important to them (e.g., "People with the same diagnosis can relate more to each other."). It was also stated that finding groups that shared a lung cancer diagnosis was difficult to find (e.g., "I was trying to find a support group, but all you can find is breast cancer."). Three participants (25.0\%) reported that their interest in a support group depended upon whether they perceived that they needed it at that time, which might increase or decrease depending on the severity of their physical and emotional distress (e.g., "Maybe if it occurred again...if I had another 
recurrence. That might change my mind. I don't know."). One-quarter $(n=3)$ of the study sample also indicated that listening to positive and hopeful stories was an important component of a support group (e.g., “...hearing their stories...their positive stories.”). Two participants (16.7\%) stated that previous experience with a support group influenced their interest level. Two participants also stated that their low interest level was influenced the desire to not talk about experiences with cancer among other people (e.g., "I always shied away from them. That may be because I don't like speaking of things like that with others.”). One participant (8.3\%) stated that interest would be high dependent on whether the group was composed of a group of professionals who would inform the individual on what to do given the individual's case (e.g., "If it was a group of doctors talking about it saying, 'This is what we can do,' that would be different."). However, four participants indicated that they would not be interest in a support group format. Interviews from two participants contained no categories under the theme of support group interest.

\section{Telephone}

Four categories emerged from rationales provided for relative interest levels in a telephone-based psychosocial intervention. Categories included convenience of telephone use, previous experience in using a telephone-based support service, receipt of reliable support (e.g., from a professional), and no interest. Three participants $(25.0 \%)$ reported that previous use of a telephone-based service influenced their interest rating. Two participants $(16.7 \%)$ stated that their high interest ratings were attributable to the convenience of a telephone-based service (e.g., "I could call a 24-hour nurse line.”). Two 
other participants indicated that having reliable support and information (e.g., from an expert) would influence their interest levels (e.g., "I could rely on the information that they give me."). Two participants indicated that they were not interested in telephonebased service. Interviews from four participants contained no text in the four categories to explain rationales for telephone use.

\section{Personal Effort}

Four categories emerged from analyzing the rationales of interest levels regarding personal effort in meeting needs: perceiving themselves as information gatherers, desiring some guidance in seeking help or information, feeling little motivation without external help, and using the Internet. Five participants (41.7\%) stated that they saw themselves as information gatherers and recalled events in which they gathered informational resources relevant to them (e.g., "I try to get information from the people I know...from all the doctors."). Four participants (33.3\%) specified that they utilized the Internet as a tool to meet their information-seeking needs (e.g., "I use the computer a lot for my health.”). One participant (8.3\%) explained that his low rating was due to needing guidance in meeting personal needs (e.g., "I would like to know where to find reliable research.”). Another participant indicated that his low interest was due to limited motivation without the external support. Interviews from two participants contained no categories to explain interest levels in implementing personal efforts to meet needs. 


\section{CHAPTER FOUR}

\section{DISCUSSION}

\section{Lung Cancer Patients’ Most Pertinent Psychosocial Needs}

Although about half (41.7\%) of the lung cancer patients in this study initially reported no current psychosocial needs, all patients indicated some psychosocial need that was pertinent to them. These findings from this study suggest that the most pertinent psychosocial needs for lung cancer patients are more information regarding lung cancer and its treatment, fatigue, and anxiety about future medical results or about negative effects from cancer (each reported by over half of the participants). This matches moderately well with the findings from Sanders et al. (2010), whose quantitative findings suggested that lack of energy or tiredness (i.e., fatigue; 75\%), uncertainty about the future $(64 \%)$, and work around the home (64\%) were the most endorsed unmet supportive care

needs. In the same study, although information about diagnosis and treatment was not the most reported unmet need, more lung cancer patients indicated interest in services offered free of charge that were geared towards meeting that need (i.e., information; $61 \%$ ) compared to any other type of service. Also, Devitt et al. (2010) found that the most desired content for a support group was information related to lung cancer and its treatment (96-78\% for specific categories of information). The rates of categories of reported psychosocial needs appeared to match well with Sanders et al. (2010). For example, Sanders and colleagues reported a slightly lower (66\%) rate of unmet need in the health system and informational domain, a similar rate of lung cancer patients who 
met the CES-D cutoff for depression (37.4\%), and a similar rate of anxiety (about 49\%) when compared to the lung cancer patients interviewed in this study.

\section{Barriers that Hinder Lung Cancer Patients’ Engagement in Psychosocial Interventions}

The barriers reported most frequently by lung cancer patients in this study were time-related and travel-related issues, followed by barriers of limited motivation or

necessity as well as limited finances. The travel barrier has been reported in the findings of Devitt et al. (2010). Besides not wanting to participate in a support group (most often reported), Devitt and colleagues found that the barriers most often expressed by lung cancer patients were difficulty with transportation and parking (38\%), not wanting to travel (37\%), and not wanting to talk about lung cancer (37\%).

\section{Lung Cancer Patients’ Interest in Specific Modes of Intervention Delivery}

The findings from this study indicated that lung cancer patients were most interested in interventions delivered via face-to-face methods. They also showed a similar level of interest in meeting their psychosocial needs for information via personal effort (i.e., limited external support). However, more lung cancer patients stated that their interest level was a five or greater for meeting their needs through personal effort $(83.3 \%)$ compared to their interest ratings given for a face-to-face format $(75 \%)$. 


\section{Internet-based Format}

Internet-based psychosocial interventions directed toward lung cancer patients may be more likely to be utilized if it is clear that it is from a reliable source (e.g., cite journal articles for informational interventions). Patients may also show more interest if Internet-based interventions advertise the breadth and depth of information that is provided by the website.

\section{Telephone-based Format}

Psychosocial interventions delivered through the telephone should focus on emphasizing its convenience to lung cancer patients, especially when time-related and travel-related barriers are apparent. Also, the credibility of the individual (e.g., the credentials) speaking to the lung cancer patient should be made clear.

\section{Support Group Format}

According to the findings of Devitt et al. (2010) and this study, it is important for lung cancer patients to be in a support group with others who are also diagnosed with lung cancer. Given that some participants in the this study indicated that the timing (i.e., whether I believe that I am currently in need of a support group now) of when the support group is offered could affect their interest, it may be useful for lung cancer patients to be clearly informed of what needs a given support group can fill. 


\section{Limitations}

This study had several limitations. Since the interviews were carried out in a cross-sectional design, lung cancer patients' experiences could be captured only at one point in time and may not reflect what their perspectives were before and after the interviews. Also, the study suffered from a low sample size $(n=12)$, which is lower than the sample size recommended ( $n=20)$ by Creswell et al. (2007). Further, the study sample is less often diagnosed at later stages of cancer progression (i.e., stage III and stage IV) and less ethnically diverse when compared to national estimates of regional (22\%) and distant (56\%) spread of cancer from the lungs and bronchus and estimates of the ethnic distribution of the age-adjusted lung cancer incidence (60.55 for white and 69.16 for black ethnic groups per 100,000 individuals in the United States in 2008; SEER). The low sample size and lack of similarity to the national population of lung cancer patients possibly bias the results from this study and limits the study's external validity.

\section{Implications for Psychosocial Intervention Development for Lung Cancer Patients}

Psychosocial interventions can address lung cancer patients' most pertinent needs if information regarding lung cancer and its treatments, fatigue-related support, and services that address patients' anxiety about future medical exam results or cancer recurrence are provided in a face-to-face format or via resources accessible by the patients (e.g., the Internet). Lung cancer patients should be offered interventions at times and locations that facilitate their engagement. Also, the intervention should be efficiently 
delivered such that as little of the patient's time is taken. If available, they should be made aware of transportation services that can deliver them to the site of the intervention and financial reimbursements for which they qualify to address travel-related and income-related barriers. Given that a lack of information about psychosocial interventions was a barrier for several patients in this study, it is important to be clear about what is offered and what involvement entails for a patient in any intervention. Considering the diversity of psychosocial needs presented by lung cancer patients in this study and across previous studies (e.g., Sanders et al., 2010 and Li \& Girgis, 2006), any psychosocial intervention should begin with a subjective needs assessment of the target population (Green \& Kreuter, 2000). After determining their available resources, psychosocial intervention developers may then find how their capabilities can meet the needs of the target population.

\section{Implications for Future Research}

Future investigations regarding psychosocial interventions addressing lung cancer patients' psychosocial needs, barriers to engage in psychosocial interventions, and preferred intervention channels, should be conducted with ethnically diverse samples that are stratified according to the national distribution of ethnic groups and cancer staging for lung cancer. Also, a longitudinal replication of this study with a larger sample of lung cancer patients ( $n \geq 20$; Creswell et al., 2007) would result in good external validity and facilitate the generalizability of findings to the theoretical population of lung cancer patients. Given that lung cancer patients have reported that their experience of stigma, shame, and blame affected their motivation to go to doctor's appointments (Chapple et 
al., 2004), it may also be informative for future research to specifically explore whether lung cancer patients' experience of stigma, self-blame, and shame might affect their interest or motivation to attend a psychosocial intervention. Although the results from this study found no barriers related to stigma, shame, or self-blame, it may be due to the low sample size (biased results) and the format of the interview (i.e., not specifically asking about self-blame, shame, or stigma). Finally, it may be informative for future investigations to explore how lung cancer patients perceive barriers to engage in psychosocial interventions according to the mode of delivery. For example, patients may perceive a different set of barriers if asked about engagement in a face-to-face intervention versus an Internet-based intervention. 


\section{REFERENCES}

Alberg, A. J., \& Samet, J. M. (2003). Epidemiology of Lung Cancer. Chest, 123(1), 21S49S. doi:10.1378/chest.123.1_suppl.21S

American Cancer Society. (2010). Cancer Facts and Figures 2010. Atlanta: American Cancer Society.

Anthonisen, N. R., Skeans, M. A., Wise, R. A., Manfreda, J., Kanner, R. E., Connett, J. E. (2005). The effects of a smoking cessation intervention on 14.5-year mortality: a randomized clinical trial. Ann Intern Med, 142(4), 233-239.

Aubin, M., Vézina, L., Verreault, R., Fillion, L., Hudon, E., Lehmann, F., Leduc, Y., et al. (2011). Family physician involvement in cancer care and lung cancer patient emotional distress and quality of life. Supportive Care in Cancer, 19(11), 17191727. doi:10.1007/s00520-010-1010-y

Badr, H., Acitelli, L. K., \& Taylor, C. L. C. (2008). Does talking about their relationship affect couples' marital and psychological adjustment to lung cancer? Journal of Cancer Survivorship, 2, 53-64. doi:10.1007/s11764-008-0044-3

Balduyck, B., Sardari, N. P., Cogen, A., Dockx, Y., Lauwers, P., Hendriks, J., Van Schil, P. (2011). The effect of smoking cessation on quality of life after lung cancer surgery. Eur J Cardiothorac Surg. [Epub ahead of print]. doi:10.1016/j.ejcts.2011.03.004

Bedor, M., Alexander, C., \& Edelman, M. J. (2005). Management of common symptoms of advanced lung cancer. Current Treatment Options in Oncology, 6(1), 61-68. Retrieved from http://www.ncbi.nlm.nih.gov/pubmed/15610715

Berendes, D., Keefe, F. J., Somers, T. J., Kothadia, S. M., Porter, L. S., \& Cheavens, J. S. (2011). Hope in the context of lung cancer: Relationships of hope to symptoms and psychological distress. Journal of Pain, The, 40(2), 174-182. doi:10.1016/j.jpainsymman.2010.01.014.Hope

Bezjak, A., Lee, C. W., Ding, K., Brundage, M., Winton, T., Graham, B., Whitehead, M., et al. (2008). Quality-of-life outcomes for adjuvant chemotherapy in early-stage non-small-cell lung cancer: results from a randomized trial, JBR.10. J Clin Oncol, 26(31), 5052-5059. doi:10.1200/JCO.2007.12.6094

Bredin, M., Corner, J., Krishnasamy, M., Plant, H., Bailey, C., \& A’Hern, R. (1999). Multicentre randomised controlled trial of nursing intervention for breathlessness in patients with lung cancer. $B M J, 318,901-904$. Retrieved from http://www.pubmedcentral.nih.gov/articlerender.fcgi? $\operatorname{artid}=27809 \&$ tool=pmcentr ez\&rendertype $=$ abstract 
Buccheri, G. (1998). Depressive reactions to lung cancer are common and often followed by a poor outcome. European Respiratory Journal, 11, 173-178.

doi:10.1183/09031936.98.11010173

Buchanan, D., Milroy, R., Baker, L., Thompson, a M., \& Levack, P. a. (2010). Perceptions of anxiety in lung cancer patients and their support network. Supportive Care in Cancer, 18, 29-36. doi:10.1007/s00520-009-0626-2

Carlsen, K., Jensen, A. B., Jacobsen, E., Krasnik, M., \& Johansen, C. (2005). Psychosocial aspects of lung cancer. Lung Cancer, 47(3), 293-300. doi:10.1016/j.lungcan.2004.08.002

Carlson, L. E., Groff, S. L., Maciejewski, O., \& Bultz, B. D. (2010). Screening for distress in lung and breast cancer outpatients: a randomized controlled trial. Journal of Clinical Oncology, 28(33), 4884-4891. doi:10.1200/JCO.2009.27.3698

Casañas i Comabella, C., Gibbons, E., \& Fitzpatrick, R. (2010). A STRUCTURED REVIEW OF PATIENT-REPORTED OUTCOME MEASURES FOR LUNG CANCER, 2010. Cancer Research, 1-45.

Cataldo, J. K., Slaughter, R., Jahan, T. M., Pongquan, V. L., \& Hwang, W. J. (2011). Measuring stigma in people with lung cancer: psychometric testing of the cataldo lung cancer stigma scale. Oncology Nursing Forum, 38(1), E46-E54. doi:10.1188/11.ONF.E46-E54

Chapple, A., Ziebland, S., \& McPherson, A. (2004). Stigma, shame, and blame experienced by patients with lung cancer: qualitative study. BMJ, 328, 1470-1475. doi:10.1136/bmj.38111.639734.7C

Chen, M. L., Chen, M. C., \& Yu, C. T. (2010). Depressive symptoms during the first chemotherapy cycle predict mortality in patients with advanced non-small cell lung cancer. Supportive Care in Cancer, 19(11), 1705-1711. doi:10.1007/s00520010-1005-8

Cooley, M. E., Sarna, L., Brown, J. K., Williams, R. D., Chernecky, C., Padilla, G., Danao, L. L., et al. (2007). Tobacco use in women with lung cancer. Annals of Behavioral Medicine, 33(3), 242-250. doi:10.1080/08836610701357989

Devitt, B., Hatton, A., Baravelli, C., Schofield, P., Jefford, M., \& Mileshkin, L. (2010). What should a support program for people with lung cancer look like? Differing attitudes of patients and support group facilitators. Journal of Thoracic Oncology, 5(8), 1227-1232. doi:10.1097/JTO.0b013e3181e004b2

Faller, H., Schilling, S., \& Lang, H. (1995). Causal attribution and adaptation among lung cancer patients. Journal of Psychosomatic Research, 39(5), 619-627. doi:10.1016/0022-3999(61)90013-7 
Faller, H., \& Schmidt, M. (2004). Prognostic value of depressive coping and depression in survival of lung cancer patients. Psycho-Oncology, 13(5), 359-363.

doi:10.1002/pon.783

Fox, S. W., \& Lyon, D. E. (2006). Symptom clusters and quality of life in survivors of lung cancer. Oncology Nursing Forum, 33(5), 931-936. doi:10.1188/06.ONF.931936

Gonzalez, B. D., \& Jacobsen, P. B. (2010). Depression in lung cancer patients : the role of perceived stigma. Psycho-Oncology. doi:10.1002/pon

Gooneratne, N. S., Dean, G. E., Rogers, A. E., Nkwuo, J. E., Coyne, J. C., \& Kaiser, L. R. (2008). Sleep and quality of life in long-term lung cancer survivors. Lung Cancer, 58(3), 403-410.

Graves, K. D., Arnold, S. M., Love, C. L., Kirsh, K. L., Moore, P. G., \& Passik, S. D. (2007). NIH Public Access. Lung Cancer, 55(2), 215-224.

Greene, K., \& Banerjee, S. (2006). Disease-related stigma: Comparing predictors of AIDS and cancer stigma. Journal of Homosexuality, 50, 185-209. doi: 10.1300/J082v50n04_08

Helsing, M., Bergman, B., Thaning, L., \& Hero, U. (1998). Quality of life and survival in patients with advanced non-small cell lung cancer receiving supportive care plus chemotherapy with carboplatin and etoposide or supportive care only. A multicentre randomised phase III trial. European Journal of Cancer, 34(7), 10361044. doi:10.1016/S0959-8049(97)10122-8

Henoch, I., Bergman, B., Gustafson-Johansson, F., \& Danielson, E. (2007). The impact of symptoms, coping capacity, and social support on quality of life experience over time in patients with lung cancer. J Pain Symptom Manage, 34(4), 370-379.

Hickok, J. T., Morrow, G. R., McDonald, S., \& Bellg, A. J. (1996). Frequency and correlates of fatigue in lung cancer patients receiving radiation therapy: implications for management. Journal of Pain and Symptom Management, 11(6), 370-377. Retrieved from http://www.ncbi.nlm.nih.gov/pubmed/8935141

Hopwood, P., \& Stephens, R. J. (2000). Depression in patients with lung cancer: prevalence and risk factors derived from quality-of-life data. Journal of Clinical Oncology, 18(4), 893-903. Retrieved from http://www.ncbi.nlm.nih.gov/pubmed/10673533

Howlader N, Noone AM, Krapcho M, Neyman N, Aminou R, Altekruse SF, Kosary CL, Ruhl J, Tatalovich Z, Cho H, Mariotto A, Eisner MP, Lewis DR, Chen HS, Feuer EJ, Cronin KA (eds). SEER Cancer Statistics Review, 1975-2009 (Vintage 2009 Populations), National Cancer Institute. Bethesda, MD, 
http://seer.cancer.gov/csr/1975_2009_pops09/, based on November 2011 SEER data submission, posted to the SEER web site, 2012.

Hung, R., Krebs, P., Coups, E. J., Feinstein, M. B., Park, B. J., Burkhalter, J., \& Ostroff, J. S. (2011). Fatigue and functional impairment in early-stage non-small cell lung cancer survivors. J Pain Symptom Manage, 41(2), 426-435.

doi:10.1016/j.jpainsymman.2010.05.017.Fatigue

Jacobsen, J., Jackson, V., Dahlin, C., Greer, J., Perez-Cruz, P., Billings, J. A., Pirl, W., et al. (2011). Components of early outpatient palliative care consultation in patients with metastatic nonsmall cell lung cancer. Journal of Palliative Medicine, 14(4), 459-464. doi:10.1089/jpm.2010.0382

Jemal, A., Thun, M. J., Ries, L. a G., Howe, H. L., Weir, H. K., Center, M. M., Ward, E., et al. (2008). Annual report to the nation on the status of cancer, 1975-2005, featuring trends in lung cancer, tobacco use, and tobacco control. Journal of the National Cancer Institute, 100(23), 1672-1694. doi:10.1093/jnci/djn389

Joyce, M., Schwartz, S., \& Huhmann, M. (2008). Supportive care in lung cancer. Seminars in Oncology Nursing, 24(1), 57-67. doi:10.1016/j.soncn.2007.11.013

Kaiser, N. C., Hartoonian, N., \& Owen, J. E. (2010). Toward a cancer-specific model of psychological distress: population data from the 2003-2005 National Health Interview Surveys. Journal of Cancer Survivorship, 4(4), 291-302. doi: $10.1007 / \mathrm{s} 11764-010-0120-3$

Kim, Y., Duberstein, P. R., Sorensen, S., \& Larson, M. R. (2005). Levels of depressive symptoms in spouses of people with lung cancer: effects of personality, social support, and caregiving burden. Psychosomatics, 46, 123-130.

Kurtz, M. E., Kurtz, J. C., Stommel, M., Given, C. W., \& Given, B. (2002). Predictors of depressive symptomatology of geriatric patients with lung cancer - a longitudinal analysis. Psycho-Oncology, 11, 12 - 22. doi:10.1002/pon.545

Langendijk, J. A., Aaronson, N. K., ten Velde, G. P., de Jong, J. M., Muller, M. J., \& Wouters, E. F. (2000). Pretreatment quality of life of inoperable non-small cell lung cancer patients referred for primary radiotherapy. Acta Oncologica, 39(8), 949-958. Retrieved from http://www.ncbi.nlm.nih.gov/pubmed/11207002

Li, J., \& Girgis, A. (2006). Supportive care needs: are patients with lung cancer a neglected population? Psycho-Oncology, 15, 509-516. doi:10.1002/pon.983

Lo, C., Zimmermann, C., Rydall, A., Walsh, A., Jones, J. M., Moore, M. J., Shepherd, F. a, et al. (2010). Longitudinal study of depressive symptoms in patients with metastatic gastrointestinal and lung cancer. Journal of Clinical Oncology, 28(18), 3084-3089. doi:10.1200/JCO.2009.26.9712 
LoConte, N. K., Else-quest, N. M., Eickhoff, J., Hyde, J., \& Schiller, J. H. (2008). Assessment of guilt and shame in patients with non-small-cell lung cancer compared with patients with breast and prostate cancer. Clinical Lung Cancer, 9(3), 171-178.

LoRusso, P. M., Herbst, R. S., Rischin, D., Ranson, M., Calvert, H., Raymond, E., Kieback, D., et al. (2003). Improvements in quality of life and disease-related symptoms in phase I trials of the selective oral epidermal growth factor receptor tyrosine kinase inhibitor ZD1839 in non-small cell lung cancer and other solid tumors. Clinical Cancer Research, 9, 2040-2048. Retrieved from http://clincancerres.aacrjournals.org/content/9/6/2040

Menec, V. H., \& Perry, R. P. (1995). Reactions to stigmas: the effect of targets' age and controllability of stigmas. Journal of Aging and Health, 7(3), 365-383. doi:10.1177/089826439500700302

Montazeri, A., Gillis, C. R., \& McEwen, J. (1998). Quality of life in patients with lung cancer: a review of literature from 1970 to 1995. Chest, 113(2), 467-481. doi:10.1378/chest.113.2.467

Myrdal, G., Valtysdottir, S., Lambe, M., \& Ståhle, E. (2003). Quality of life following lung cancer surgery. Thorax, 58, 194-197. Retrieved from http://www.pubmedcentral.nih.gov/articlerender.fcgi?artid=1746612\&tool=pmce ntrez\&rendertype $=$ abstract

Nakaya, N., Saito-Nakaya, K., Akizuki, N., Yoshikawa, E., Kobayakawa, M., Fujimori, M., Nagai, K., et al. (2006). Depression and survival in patients with non-small cell lung cancer after curative resection: a preliminary study. Cancer Science, 97(3), 199-205. doi:10.1111/j.1349-7006.2006.00160.x

Naughton, M. J., Herndon, J. E., Shumaker, S. A., Miller, A. A., Kornblith, A. B., Chao, D., \& Holland, J. (2002). The health-related quality of life and survival of smallcell lung cancer patients: results of a companion study to CALGB 9033. Quality of Life Research, 11, 235-248. Retrieved from

http://www.ncbi.nlm.nih.gov/pubmed/12074261

Okuyama, T., Tanaka, K., Akechi, T., Kugaya, A., Okamura, H., Nishiwaki, Y., Hosaka, T., et al. (2001). Fatigue in ambulatory patients with advanced lung cancer: prevalence, correlated factors, and screening. Journal of Pain and Symptom Management, 22(1), 554-564. Retrieved from http://www.ncbi.nlm.nih.gov/pubmed/11516597

Owen, J. E., Goldstein, M. S., Lee, J. H., Breen, N., \& Rowland, J. H. (2007). Use of health-related and cancer-specific support groups among adult cancer survivors. Cancer, 109(12), 2580-2589. doi:10.1002/cncr.22719 
Pinto, B. M., Eakin, E., Maruyama, N. (2000). Health behavior changes after a cancer diagnosis: what do we know and where do we go from here? Annals of Behavioral Medicine, 22, 38-52.

Porter, L. S., Keefe, F. J., Garst, J., Baucom, D. H., McBride, C. M., McKee, D. C., Sutton, L., et al. (2011). Caregiver-assisted coping skills training for lung cancer: results of a randomized clinical trial. Journal of Pain and Symptom Management, 41(1), 1-13. Elsevier Inc. doi:10.1016/j.jpainsymman.2010.04.014

Roddy, E., Antoniak, M., Britton, J., Molyneux, A., \& Lewis, S. (2006). Barriers and motivators to gaining access to smoking cessation services amongst deprived smokers--a qualitative study. BMC Health Services Research, 6, 147-153. doi:10.1186/1472-6963-6-147

Sanders, S. L., Bantum, E. O., Owen, J. E., Thornton, A. A., \& Stanton, A. L. (2010). Supportive care needs in patients with lung cancer. Psycho-Oncology, 19, 480489. doi:10.1002/pon.1577

Sarna, L., Cooley, M. E., Brown, J. K., Chernecky, C., Padilla, G., Danao, L., Chakravarty, D., et al. (2010). Women with lung cancer: quality of life after thoracotomy: a 6-month prospective study. Cancer Nursing, 33(2), 85-92. doi:10.1097/NCC.0b013e3181be5e51

Slotman, B. J., Mauer, M. E., Bottomley, A., Faivre-Finn, C., Kramer, G. W. P. M., Rankin, E. M., Snee, M., et al. (2009). Prophylactic cranial irradiation in extensive disease small-cell lung cancer: short-term health-related quality of life and patient reported symptoms - results of an international phase III randomized controlled trial by the EORTC radiation oncology and lun. Journal of Clinical Oncology, 27(1), 78-84. doi:10.1200/JCO.2008.17.0746

Snyder, C. R. (2002). Hope theory: rainbows in the mind. Psychol Inq, 13, 249-275.

Spitzer, R. L., Williams, J. B. W., Gibbon, M., First, M. B. (1990). Structured Clinical Interview for DSM-III-R. Washington, DC: American Psychiatric Press.

Stone, P., Richards, M., A’Hern, R., \& Hardy, J. (2000). A study to investigate the prevalence, severity and correlates of fatigue among patients with cancer in comparison with a control group of volunteers without cancer. Annals of Oncology, 11, 561-567.

Taenzer, P., Bultz, B. D., Carlson, L. E., Speca, M., DeGagne, T., Olson, K., Doll, R., et al. (2000). Impact of computerized quality of life screening on physician behaviour and patient satisfaction in lung cancer outpatients. Psycho-Oncology, 9, 203-13. Retrieved from http://www.ncbi.nlm.nih.gov/pubmed/10871716 
Tchekmedyian, N. S., Kallich, J., McDermott, A., Fayers, P., \& Erder, M. H. (2003). The relationship between psychologic distress and cancer-related fatigue. Cancer, 98(1), 198-203. doi:10.1002/cncr.11463

Temel, J. S., Greer, J. a, Muzikansky, A., Gallagher, E. R., Admane, S., Jackson, V. a, Dahlin, C. M., et al. (2010). Early palliative care for patients with metastatic nonsmall-cell lung cancer. The New England Journal of Medicine, 363(8), 733-742. doi:10.1056/NEJMoa1000678

Uchitomi, Y., Mikami, I., Nagai, K., Nishiwaki, Y., Akechi, T., \& Okamura, H. (2003). Depression and psychological distress in patients during the year after curative resection of non-small-cell lung cancer. Journal of Clinical Oncology, 21(1), 6977. doi:10.1200/JCO.2003.12.139

Villeneuve, P. J., \& Mao, Y. (1994). Lifetime probability of developing lung cancer, by smoking status, Canada. Can J Public Health, 85(6), 385-388.

Walker, M. S., Larsen, R. J., Zona, D. M., Govindan, R., \& Fisher, E. B. (2004). Smoking urges and relapse among lung cancer patients: findings from a preliminary retrospective study. Preventive Medicine, 39(3), 449-457. doi:10.1016/j.ypmed.2004.04.035

Wu, J., \& Sin, D. D. (2011). Improved patient outcome with smoking cessation: when is it too late? International Journal of COPD, 6, 259-267. doi:10.2147/COPD.S10771

Yang, P. (2009). Epidemiology of lung cancer prognosis: quantity and quality of life. Methods Mol Biol, 471, 469-486. Totowa, NJ: Humana Press. doi:10.1007/978-159745-416-2_24

Yardley, S., Davis, C., \& Sheldon, F. (2001). Receiving a diagnosis of lung cancer: patients' interpretations, perceptions and perspectives. Palliative Medicine, 15(5), 379-386. doi:10.1191/026921601680419429

Zabora, J., Brintzenhofeszoc, K., Curbow, B., Hooker, C., \& Piantadosi, S. (2001). The prevalence of psychological distress by cancer site. Psycho Oncology, 10, 19-28. 


\section{APPENDIX}

\section{Telephone Script}

Hello, this is Kevin Criswell from Loma Linda University. May I speak with (patient's name)? Hello (patient's name). I am calling on behalf of Dr. Jason Owen. We received your completed questionnaire and I would like to thank you for taking the time to complete and return it. After reviewing your responses, I noticed that you might be interested in participating in future research. Did you receive the letter I sent you?

(If patient responds "Yes," then proceed with the telephone script.)

(If patient responds "No," then explain that a letter was sent containing a consent sheet as well as a letter, notifying that he/she will receive a call from a researcher within the next two weeks. Then proceed with the telephone script.)

I am making this call to ask you to take part in a telephone interview, which may take about 20 minutes. It will involve questions about nonmedical needs you have, how you would like those needs to be met, and any difficulties you find in obtaining those needs. The interview will be recorded and transcribed for use in our study. To thank you for your time, you will be reimbursed with a \$20 gift card to Target. At the conclusion of the study, the recording and its transcription will be destroyed to protect your confidentiality. Would you be willing to take part in this interview?

(If patient responds "No,” then reply, “Thank you for your time. Goodbye.”)

(If patient responds "Yes," then reply with the following script.)

Thank you. Is it okay if we begin the interview now or would you like to schedule a later time for the interview? 
(If patient responds by saying that he/she would like to begin the interview now, then reply with the following script.)

We will start in just a moment. Please keep in mind that you may choose to end the interview at any time. (Skip to the Interview Schedule.)

(If patient responds by saying that he/she would like schedule the interview at another time, then reply with the following script.)

When would you like to schedule our interview? (Record the time that the participant and an investigator can mutually agree on.) Okay, I will be calling you back on [recite the agreed time to conduct the interview]. Thank you for your time. Goodbye.

\section{Scheduled Interview Call}

Hello, this is Kevin Criswell from Loma Linda University. May I speak with (patient's name)? Hello (patient's name). I called you a while ago to ask if you could take part in an interview about any nonmedical needs you have, how you would like those needs to be met, and any difficulties you find in obtaining those needs. When we talked, you had mentioned that this time would work for taking part in this interview. Are you ready to begin the interview?

(If patient responds by saying that he/she would like to begin the interview now, then reply with the following script.)

We will start in just a moment. Please keep in mind that you may choose to end the interview at any time. (Skip to the Interview Schedule.)

(If patient responds by saying that he/she would like schedule the interview at another time, then reply with the following script.) 
When would you like to schedule our interview? (Record the time that the participant and an investigator can mutually agree on.) Okay, I will be calling you back on [recite the agreed time to conduct the interview]. Thank you for your time. Goodbye.

(If patient responds by saying that he/she does not want to participate, then reply, “Okay. Thank you for your time. Goodbye.”)

\section{Interview Schedule}

(Begin recording the interview.)

1. Please think about how you are currently living with your cancer every day.

When you think about it, what types of needs do you usually require help with?

(Probe: Of those needs, which would you consider to be the most important to you?

Why? On a scale from one to ten, one being little to no interest and ten being extremely interested, how interested are you in receiving support for your most important need? Why?)

2. On a scale from one to ten, one being little to no interest and ten being extremely interested, what is your level of interest in the following ways of meeting your needs:

- Internet _ Why is it a (the number the patient indicated for Internet)?

- Face-to-face __ Why is it a (the number the patient indicated for Face-to-face)?

- A group of others who have also been diagnosed with lung cancer ___ _ Why is it a (the number the patient indicated for a lung cancer support group)?

- Telephone __ Why is it a (the number the patient indicated for Telephone)?

- On your own (e.g., reading materials, website, etc.) __ Why is it a (the number the patient indicated for personal research)? 
3. Now, I am going to ask you about what you think might get in the way of seeking help for any of your needs. Some of these roadblocks for seeking help can include personal, social, physical, financial, or other areas of life. Please tell me specifically why you would find it difficult to seek help to get your needs met.

(Probe: Of those difficulties, which do you consider most troublesome? Why?)

4. At the place where you receive or have received treatment for your cancer, have you been given information about any support services that you are eligible to receive? (Probe if any services are recalled: Can you recall what services are offered? Of those services that you recall, which ones interest you the most?)

5. Are there any other things that you would like to mention before we end the interview?

(Stop recording the interview.)

Thank you for your time. Your responses will be kept confidential and will help us to develop more effective nonmedical services for lung cancer patients. Also, you will receive your $\$ 20$ reimbursement by mail. Have a good day.

(Hang up the phone.) 